\title{
Narrative dialogic reading with wordless picture books: A cluster-randomized intervention study
}

\author{
Lorenz Grolig, Caroline Cohrdes, Simon P. Tiffin-Richards, and Sascha Schroeder \\ Max Planck Institute for Human Development, Berlin
}

\begin{abstract}
Author Note
Lorenz Grolig, Caroline Cohrdes, Simon P. Tiffin-Richards, and Sascha Schroeder, Max Planck Research Group Reading Education and Development (REaD), Max Planck Institute for Human Development, Berlin, Germany.

Lorenz Grolig is now at the Senate Department of Education, Youth, and Family, Berlin, Germany. Caroline Cohrdes is now at the Department of Epidemiology and Health Monitoring, Robert Koch Institute, Berlin, Germany. Simon P. Tiffin-Richards is now at the Department of Psychology, University of Würzburg, Germany. Sascha Schroeder is now at the Department of Educational Psychology, University of Göttingen, Germany.

Correspondence concerning this article should be addressed to Lorenz Grolig: Reading Education and Development (REaD), Max Planck Institute for Human Development, Lentzeallee 94, 14195 Berlin, Germany. Email: grolig@posteo.de

This work was supported by Forschungsfonds Kulturelle Bildung (Rat für kulturelle Bildung and Stiftung Mercator) [grant number 14-001-4]. We thank Maike Hille, Nicola Hohensee, Ann-Katrin Hosch, Iuna Hoffmann, Ye-Young Hwang, Janis Keck, Pia Linscheid, Laura Prieß, Sarah-Lena Schaefer, and Anna Walther for their assistance in conducting this study. We also thank all participating children and parents, child care centers, and teachers for supporting this study.

(C) 2019. This manuscript version is made available under the CC-BY-NC-ND 4.0 license http://creativecommons.org/licenses/by-nc-nd/4.0/
\end{abstract}

Please cite as: Grolig, L., Cohrdes, C., Tiffin-Richards, S. P., \& Schroeder, S. (2020). Narrative dialogic reading with wordless picture books: A cluster-randomized intervention study. Early Childhood Research Quarterly, 51, 191-203. doi:10.1016/j.ecresq.2019.11.002

Supplemental materials are available after the References section of this document. 


\begin{abstract}
Shared reading has the potential to promote a wide range of language skills that are important for reading acquisition. Dialogic reading interventions in preschool facilitate the acquisition of vocabulary and narrative production skills, but it is unclear (a) whether dialogic reading can also foster inferential and literal narrative comprehension and (b) whether intervention effects are maintained until the beginning of formal reading instruction. To close these two gaps, we designed and conducted a low-dose narrative dialogic reading intervention with wordless picture books. On the child care center level, 201 German preschoolers ( $M_{\text {age }}=5 ; 5$ years $)$ were randomly assigned to the dialogic reading group, an alternative treatment group, or a no treatment group. Hierarchical linear models showed positive effects of dialogic reading on inferential and literal narrative comprehension and on vocabulary depth and breadth. The effect on inferential narrative comprehension was maintained five months after posttest. Overall, our findings indicate that even a small amount of narrative dialogic reading has small, albeit mostly short-term effects on narrative comprehension and vocabulary skills. We conclude that narrative dialogic reading is a promising approach for supporting the development of preschoolers' inferential skills. Long-term intervention studies are needed for the evaluation of long-term effects.
\end{abstract}

Keywords: dialogic reading intervention, wordless picture books, comprehension, inference, narrative, follow-up 
Narrative dialogic reading with wordless picture books: A cluster-randomized intervention study Introduction

\section{Introduction}

Preschool children with well-developed oral language skills, such as vocabulary and narrative skills, are more likely to become proficient readers (Griffin, Hemphill, Camp, \& Wolf, 2004; Lepola, Lynch, Kiuru, Laakkonen, \& Niemi, 2016; Lepola, Lynch, Laakkonen, Silvén, \& Niemi, 2012; Silva \& Cain, 2015). A high proficiency in reading comprehension enables children to access a vast array of knowledge sources, including fiction and non-fiction books. Before they acquire reading skills, children often enjoy looking at picture books and making sense of picture sequences that form a narrative. Apart from being fun, talking about stories from books with an adult can help children to acquire oral language skills because children's books contain vocabulary and narratives that young children rarely encounter in other situations (Massaro, 2015; Montag, Jones, \& Smith, 2015). Using children's books for collaborative informal learning activities (referred to as shared reading) is more effective when adults use communicative strategies that activate and scaffold children's thinking (Blewitt, Rump, Shealy, \& Cook, 2009; Wasik, Hindman, \& Snell, 2016; Zucker, Cabell, Justice, Pentimonti, \& Kaderavek, 2013). A specific set of shared reading techniques known as dialogic reading fosters various oral language skills by encouraging children's active participation during shared reading (Lonigan, Purpura, Wilson, Walker, \& Clancy-Menchetti, 2013; Whitehurst et al., 1994; Zevenbergen, Whitehurst, \& Zevenbergen, 2003). In this study, we investigate the effects of a dialogic reading intervention that targets both vocabulary and narrative skills. Our study expands previous research by (a) modifying the dialogic reading intervention in the light of experimental and intervention research on shared reading effectiveness, (b) investigating intervention effects 
on different vocabulary and narrative skills, and (c) evaluating the maintenance of intervention gains until the beginning of formal reading instruction.

\section{Fostering Oral Language Skills with Picture Books and Extratextual Talk}

Picture books possess special linguistic and graphic features that make them multifunctional tools for promoting oral language skills in early childhood. For example, they contain more low frequency words (and illustrations of those words) than average child-directed speech and thus facilitate the acquisition of vocabulary knowledge (Massaro, 2015; Montag et al., 2015). Also, the stories in picture books often follow an episodic narrative structure that consists of the following story grammar elements: an exposition, an initiating event, which is followed by an internal response and an internal plan, leading to a resolution attempt, and a reaction to the outcome of this attempt (Stein \& Glenn, 1979). Discussing such stories facilitates the acquisition of narrative knowledge (Lever \& Sénéchal, 2011; Zevenbergen et al., 2003). When adults and children look at a picture book, this allows a self-paced co-construction of meaning between children and adults during which adults can adjust their scaffolding activities, such as explanations of concepts and relationships, to the children's level of comprehension (van Kleeck, Gillam, Hamilton, \& McGrath, 1997). This adaptability to children's needs renders picture books particularly suitable for learning a broad range of oral language skills.

Picture books with text have often been used in shared reading studies with typically developing children (Wasik et al., 2016). Wordless picture books, by contrast, have mostly been used in interventions targeting oral language skills of children with special needs due to language impairments, autism, or deafness (Arizpe, 2013). For typically developing pre-readers, using wordless picture books with a clear-cut, linear plot is likely to support early narrative skills because such books offer a sequence of pictures that form a narrative without relying on 
decoding skills (Paris \& Paris, 2003). In addition, children and teachers produce more diverse words (higher lexical diversity) during shared reading with wordless picture books than with text-based storybooks (Chaparro-Moreno, Reali, \& Maldonado-Carreno, 2017). By contrast, teachers produce longer sentences with text-based storybooks than with wordless picture books (Chaparro-Moreno et al., 2017), which is probably due to written sentences in storybooks being longer than spoken sentences in child-directed speech (Cameron-Faulkner \& Noble, 2013; Montag, 2019). Therefore, using wordless picture books during shared reading is likely to be more effective in fostering vocabulary skills and less effective in fostering grammatical skills in comparison to using storybooks with text.

When adults ask comprehension questions about concepts and events of a story, often referred to as extratextual talk (Blewitt et al., 2009), this can significantly increase the effects of shared reading. Children learn more words during shared reading when they are engaged in extensive extratextual talk that includes literal and inferential comprehension questions (i.e., questions about explicit and implicit story information, respectively; Zucker, et al., 2013) and when the cognitive demand level of comprehension questions is adequate for them (Blewitt et al., 2009; Mascareño, Snow, Deunk, \& Bosker, 2016). Low demand questions aim to establish a basic understanding of the vocabulary and the story line. By contrast, high demand questions encourage children to draw inferences about vocabulary and story elements. If low demand questions are followed by high demand questions, this has a stronger effect on children's vocabulary than low demand questions alone (Blewitt et al., 2009). To target a broad range of oral language skills, the intervention in this study includes low demand questions, which target literal narrative comprehension (e.g., characters, setting, and events), and high demand questions, which target inferential narrative comprehension (e.g., inferencing thoughts, dialogues, and 
feelings). Previous studies have shown that using both question types in shared reading is important for the development of inferential and literal narrative comprehension skills in preschool because both explain a substantial unique proportion of reading comprehension differences in elementary school (e.g., Silva \& Cain, 2015).

\section{Effects of Dialogic Reading on Vocabulary and Narrative Skills}

Numerous studies conducted under controlled laboratory conditions have shown that extratextual talk has positive effects on children's word learning (Flack, Field, \& Horst, 2018). By contrast, there are less intervention studies that investigated the effects of extratextual talk in ecologically more valid child care settings over a timespan of several weeks or months. Dialogic reading is an intervention in which adults and children engage in a conversation over picture books. One main aim of dialogic reading is to facilitate the acquisition of oral language skills in preschool because these skills predict how well children acquire reading comprehension skills in elementary school (Griffin et al., 2004; Lepola et al., 2016; Lepola et al., 2012). Adults support children in making sense of the concepts and events in the story (Whitehurst et al., 1994), which facilitates the acquisition of vocabulary and narrative skills (Lever \& Sénéchal, 2011; Whitehurst et al., 1999; Zevenbergen et al., 2003). Dialogic reading encourages the active participation of children in the shared reading situation and supports their oral language skills by using openended questions among other communicative strategies (Zevenbergen \& Whitehurst, 2003). Previous dialogic reading studies have used children's books that contained narratives in text form and some illustrative pictures, and thus adults actually read to children during the original intervention (e.g., Whitehurst et al., 1999; Zevenbergen et al., 2003). In the present study, mostly wordless picture books were used because they facilitate children's narrative and vocabulary learning activities even more than storybooks with text (Chaparro-Moreno et al., 2017). 
Vocabulary Breadth and Vocabulary Depth. Traditionally, dialogic reading interventions have targeted, among oral language skills, vocabulary breadth and depth. Vocabulary breadth refers to the number of words a child knows. This vocabulary skill is often measured by presenting illustrations of objects and asking children to name them, thus estimating whether a child has basic (superficial) knowledge of words (e.g., What is this? This is an igloo). By contrast, vocabulary depth refers to the number of semantic features known for familiar words, that is, the essential conceptual components of a word's meaning. This vocabulary skill is often measured through definition production tasks (Ouellette, 2006), thus estimating the refined (deep) knowledge about the meaning of a word (e.g., What is a shoe? A shoe keeps feet warm and protects them).

Many studies with preschoolers found intervention effects at posttest (e.g., Lever \& Sénéchal, 2011; Whitehurst et al., 1994), but only few studies have evaluated the maintenance of effects after preschool. Whitehurst and colleagues (1999) found a small effect on vocabulary breadth at the end of kindergarten, one year after posttest. Another study found, in contrast, that a small short-term effect on vocabulary breadth was not maintained at the beginning of first grade, three months after posttest (Sim, Berthelsen, Walker, Nicholson, \& Fielding-Barnsley, 2014). Moreover, no previous study has investigated the maintenance of dialogic reading effects on vocabulary depth. Overall, there is scarce and diverging evidence regarding the maintenance of dialogic reading effects on vocabulary breadth and depth.

Narrative Production and Narrative Comprehension. Whereas many studies have investigated intervention effects of dialogic reading on vocabulary skills (Mol, Bus, \& de Jong, 2009), few have investigated intervention effects on narrative skills (Lever \& Sénéchal, 2011; van Kleeck, Vander Woude, \& Hammett, 2006; Zevenbergen et al., 2003). With respect to 
narrative production skills, Zevenbergen and colleagues (2003) found that after children participated in a dialogic reading intervention, they included more inferences (internal states and dialogue) in their narratives than children in a no treatment group. Similar to this result, Lever and Sénéchal (2011) found that children in a dialogic reading group produced more story grammar units (inferential and literal information combined) in their posttest narratives than children in an alternative treatment group. Both studies show that dialogic reading fosters narrative production skills, but they did not differentiate between intervention effects on inferential versus literal narrative skills or investigate the maintenance of effects after posttest.

It is important to distinguish between literal and inferential narrative skills because both are necessary for the formation of a coherent situation model of a story (Kintsch, 1998). From a pedagogical perspective, it is important to ask young children literal questions in addition to inferential questions because it encourages their active participation and facilitates inferences, which are based on literal comprehension (van Kleeck, 2008). Intervention effects on narrative comprehension skills were investigated in a study in which a small sample of children with language impairments participated in a one-on-one dialogic reading intervention with scripted comprehension questions (van Kleeck et al., 2006). The intervention resulted in significant posttest gains in literal and inferential narrative comprehension (increase of $13 \%$ for each measure) in comparison to a no treatment group (van Kleeck et al., 2006). It is unclear, however, whether dialogic reading also promotes literal and inferential narrative comprehension in a small group setting with typically developing children, and whether such effects would be maintained after posttest. 


\section{Do Narrative Comprehension Questions Facilitate the Acquisition of Narrative Skills?}

Using comprehension questions during shared reading training sessions helps young children to acquire a framework that supports their narrative comprehension and their creation of coherent mental story representations (e.g., Morrow, 1984; van den Broek, Kendeou, Lousberg, \& Visser, 2011). Even though previous studies have shown that dialogic reading has a positive effect on narrative skills, less is known about how children acquire these skills during dialogic reading. As the questions used in dialogic reading activities were not specifically designed to foster narrative skills (Lever \& Sénéchal, 2011; van Kleeck et al., 2006, Zevenbergen et al., 2003), children presumably acquired narrative knowledge through incidental learning when they processed the stories with the help of an instructor. By contrast, it is unclear whether using specific narrative comprehension questions that guide children through the narrative structure of stories during the dialogic reading intervention improves their narrative production skills. Two experimental studies with five-year-olds investigated the immediate effects of narrative comprehension questions on narrative production in a shared reading setting (Silva \& Cain, 2017; Silva, Strasser, \& Cain, 2014). Both studies found that answering narrative comprehension question about a wordless picture book story prior to looking at and narrating the story of the same book had a positive effect on the quality of children's narratives: If children first answered narrative comprehension questions and then narrated the story, this resulted in a higher amount of inferential and literal information in children's narratives in comparison to the experimental condition in which children first narrated the story and then answered narrative comprehension questions. Thus, using narrative comprehension questions had a positive effect on the subsequent narrative production. Presumably, the questions functioned as cues for story grammar elements, which subsequently helped the children to produce these elements in their narratives. The two 
studies, however, do not provide conclusive evidence regarding the question whether this experimental effect is due to a questions-induced change of narrative schemata or rather due to comprehension questions momentarily guiding children's attention to relevant information (Silva \& Cain, 2017; Silva et al., 2014). Therefore, the dialogic reading routine in this study includes a set of narrative comprehension questions that is used with every story book, with the aim of fostering both narrative comprehension and production skills over an extended period of time. If this repeated exposure to narrative comprehension questions results in a persistent transformation of children's narrative schemata, then children's narrative productions should include more literal and inferential information even if their narration is not preceded by guiding comprehension questions.

\section{The Present Study}

The current study investigates effects of a narrative dialogic reading intervention on narrative and vocabulary skills by using a cluster-randomized pre-post between-subjects design with two follow-up measurement points. This study compares oral language skills in a dialogic reading group with the development of oral language skills in a music intervention group (alternative treatment) and a no treatment group between the beginning of the final preschool year and the end of Grade 1. Based on the small to medium effect sizes reported in meta-analyses about the effects of interactive reading interventions on vocabulary learning (Mol, et al., 2009; Noble et al., 2019), we expect small to medium short-term intervention effects. To account for individual differences and effects of shared reading activities outside our intervention, we control for children's storybook exposure, verbal short-term memory, and nonverbal intelligence in our analyses (Grolig, Cohrdes, Tiffin-Richards, \& Schroeder, 2019; Silva \& Cain, 2015). The present study focuses on three related research questions. 
First, we examine whether dialogic reading with mostly wordless picture books is effective in promoting inferential and literal narrative comprehension in a small group setting with typically developing children, and whether such effects are maintained after posttest. Based on previous findings (Lever \& Sénéchal, 2011; van Kleeck et al., 2006; Zevenbergen et al., 2003), we expect dialogic reading to improve inferential and literal narrative comprehension skills.

Second, we investigate whether exposure to narrative comprehension questions during the intervention also improves children's inferential and literal narrative production skills. As the intervention directly targets narrative comprehension skills, we expect that intervention effects on narrative comprehension are stronger than transfer effects on narrative production.

Third, we evaluate effects of dialogic reading on vocabulary breadth and vocabulary depth, and the maintenance of these effects until the beginning of formal reading instruction, one year after posttest. As dialogic reading with five-year-olds not only targets vocabulary breadth, but also aims to deepen the understanding of words (Zevenbergen \& Whitehurst, 2003), we expect similar positive effects on both outcome measures. We have no specific expectations regarding the maintenance of effects due to mixed results in previous dialogic reading studies (Sim et al., 2014; Whitehurst et al., 1999).

\section{Method}

\section{Participants and Procedure}

We recruited 201 children at the beginning of their last preschool year from 32 child care groups ( 90 girls; Mage $=5$ years 5 months, $\mathrm{SD}=4.4$ months) that were located at 15 child care centers in a large German city. Parental consent was obtained for all participating children. Parents completed a questionnaire in which they indicated whether their child would start school 
in the next year. They also provided information about the socioeconomic background (ISEI-08 scores; Ganzeboom \& Treiman, 1996), indicating a middle class sample, $\mathrm{M}=60.6(\mathrm{SD}=16.6)$. All children spoke German, and 54 of them (27\%) spoke an additional language. The most frequent languages were Turkish (8), English (7), French (5), Polish (4), Russian (4), and Spanish (4).

As we aimed to investigate the maintenance of intervention effects on the development of oral language skills in Grade 1, only those children were included in the study whose parents had indicated school entry in the next year. Age-standardized pretest scores in a word definition task, a nonverbal intelligence test, and a verbal short-term memory test indicated that all children were within 2.5 standard deviations of the age norm mean for the three measures (see Measures).

Children were randomly assigned on the child care center level to one of three conditions: dialogic reading, alternative treatment, or no treatment. Data were collected at four measurement points: pretest at the beginning of the final preschool year (September and October 2015); posttest at the ending of the final preschool year (May and June 2016); first-follow-up at the beginning of Grade 1 (October and November 2016); second follow-up at the ending of Grade 1 (May and June 2017). At pretest and posttest, children were individually tested at their child care center in two assessment sessions, each lasting for 40 minutes. Children received a small present after each testing session. At pretest, children also completed a nonverbal intelligence test in small groups of up to six children. For the first and the second follow-up in Grade 1, the children participated in a 60 minutes session at our test rooms. At first and second follow-up, children received a small present; parents received 15 Euros as compensation.

Overall, we tested 201 children at pretest, 193 children at posttest, 146 children at first follow-up, and 135 children at second follow-up. The drop out was 33\% between pretest and 
second follow-up, which is comparable to the drop out in developmental studies that span about two years (Sénéchal \& LeFevre, 2002). Between pretest and posttest, eight children (4\%) left their child care centers and did not participate in any further measurement points. Between posttest and the first follow-up measurement, there was further attrition (23\%). In Germany, there are no strict regulations regarding school entry at a certain age, and many parents make use of the option to keep their child in child care for an additional year. Even though all parents had indicated that their children would start school after posttest, the parents of 24 children had decided that their children would not enter Grade 1. In addition, 23 children had moved to another part of Germany or were not available for assessment. Between the first and the second follow-up measurement point, there was a further drop out of eleven children $(6 \%)$ who were not available for assessment. We tested whether there were systematic differences between children who completed the study and children who dropped out. A logistic regression showed that older children were more likely to complete the study than younger children, $\chi^{2}(1)=5.27, p<.05$. By contrast, treatment, $\chi^{2}(2)=4.43, p=.10$, control variables, all $\chi \mathrm{s} 2(1)<3.47$, all ps $>.06$, and vocabulary depth, $\chi^{2}(2)=0.38, p=.54$, were not related to the likelihood of completing the study.

\section{Treatments}

The current study reports data from the MusiCo project that investigated the effects of a language and a music intervention during the last preschool year before school entry (Schroeder \& Grolig, 2018). The language intervention combined dialogic reading with a phonological awareness training. In the present study, we focus on the effects of dialogic reading on narrative and vocabulary skills. In each intervention, children participated twice a week in sessions that 
lasted for 45 minutes. Each intervention program comprised a total of 42 sessions over six months.

The overall potential treatment time of the language intervention program was 31 hours and 30 minutes (42 sessions that lasted for 45 minutes). The dialogic reading part lasted for 20 minutes in each session, with the remaining 25 minutes in each session being used for warm-up and phonological awareness games. To maintain the children's interest in the narrative comprehension questions, they were used only in 36 of the 42 intervention sessions (three books, each being used twice during the intervention, contained target vocabulary but not narratives). Therefore, the overall potential dosage of dialogic reading was 14 hours, but the overall potential exposure to narrative comprehension questions during dialogic reading was only 12 hours.

The interventions were administered in small groups of four to eleven children (language intervention: $M=8.5, S D=2.1$; music intervention: $M=7.3, S D=1.5)$. Interventions were administered by research assistants who had an academic background and professional experience in language pedagogy or clinical linguistics (dialogic reading) or music pedagogy (alternative treatment). All research assistants were professionally trained to work with young children and had worked in a child care setting prior to the study.

Dialogic reading. We selected 19 age-appropriate picture books (16 narrative books plus two wimmelbooks1 and one rhyming book to provide a more diverse program to the children and maintain their interest in the training; see supplemental materials, Table S1). Only the narrative books had a clear storyline and contained no or very few words. Wordless picture books were 
selected because they allow children to engage in narrative activities without relying on the decoding abilities of adults (Paris \& Paris, 2003), which in turn should support their acquisition of narrative skills. Books were also selected on the basis that they contained some of the targeted vocabulary that was assessed by a standardized test of vocabulary depth (vocabulary subtest of the German Wechsler Preschool and Primary Scale of Intelligence; Petermann, 2009). To sustain interest in the books, each book was used in two sessions that were three months apart. All children were exposed to the same picture books and were asked the same standardized narrative comprehension questions.

The intervention used the dialogic reading principles developed by Whitehurst and colleagues (Whitehurst et al., 1994; Zevenbergen et al., 2003). In contrast to previous dialogic reading research, this intervention focused on story-specific questions that were designed to foster the inferential and literal comprehension of story elements. The story-related questions were the same type of questions that were used in the narrative task for the assessment of narrative comprehension (Paris \& Paris, 2003; see Measures and supplemental materials). Half of them were high demand questions that targeted inferential story grammar elements (dialogue, feelings, thoughts, prediction, theme), and half of them were low demand questions that targeted literal story grammar elements (characters, setting, initiating event, problem identification, resolution). These story-specific questions were complemented by the general communicative strategies of dialogic reading used with five-year-olds (Zevenbergen \& Whitehurst, 2003), such as open-ended prompts, "wh"-questions (e.g., what, where, why), and distancing prompts that relate story contents to children's life experiences.

In each session, these basic dialogic reading questions were used to facilitate a basic understanding of the story. Next, instructors asked the story-specific narrative comprehension 
questions to highlight the story elements. To standardize the intervention procedure, the manual included scripts for each book that included (a) questions about target vocabulary (labelling, definitions, relating concepts to children's experiences) and (b) the inferential and literal narrative comprehension questions about story-specific content.

Alternative treatment. This intervention was based on an early music education program (Nykrin, Grüner, \& Widmer, 2007) and focused on tonal discrimination, rhythm repetition, and synchronization. Further information on this intervention and results regarding music abilities are reported in Cohrdes, Grolig, and Schroeder (2019).

\section{Measures}

Narrative skills. We adapted a narrative task by Paris and Paris (2003) that has previously been used for the assessment of literal and inferential narrative skills (Lepola et al., 2012; Silva \& Cain, 2015; Silva et al., 2014). Several studies have demonstrated that there are substantial concurrent and predictive correlations of literal and inferential oral narrative comprehension scores with literal and inferential reading comprehension scores (Silva \& Cain, 2015; Lepola et al.; Paris \& Paris, 2003), confirming that the task has a high validity with respect to early reading comprehension skills. To avoid memory effects and preserve the children's interest in the task, we used a different picture book at each measurement point (see supplemental materials, Table S2; Krahn, 1979; Mayer, 1969, 1973, 1975). All four books have been used in narrative development studies with young children (Paris \& Paris, 2003; Silva \& Cain, 2015, Lepola et al., 2012) and were equivalent in that they were (a) wordless picture books with black and white drawings, (b) contained about two thirds of literal main points and one third of inferential main points, and (c) had a clear-cut storyline. 
The narrative task consisted of three parts: First, a picture walk during which children looked through the book and endeavored to comprehend the story; second, a narrative production task; third, narrative comprehension questions. As we were interested in the specific effects of dialogic reading, separate scores for inferential and literal narrative skills were calculated both for the production task and the comprehension task.

Narrative production. After the picture walk, children were asked to tell the story with the book as a prompt. The stories were recorded via headsets and transcribed afterwards. Children were told that a fictional character (the mascot of the study) was sick at home, and that he could hear the narration of the child via the headset, but that he could not see the pictures of the book. Thus, children were encouraged to tell an engaging, comprehensive story that did not omit details that were visually present in the book. Before coding children's data, main points of each story were empirically determined in a pilot study (Yuill \& Oakhill, 1991; see supplemental materials, Tables S4-S7, for details). We collected 30 oral narratives from university students for each book, transcribed them, and determined which story grammar units (Paris \& Paris, 2003; Stein \& Glenn, 1979) were mentioned by $60 \%$ or more of them (see Wright, Capilouto, Srinivasan, \& Fergadiotis, 2011, for methodological details).

Inferential production units included dialogue, feeling, thought, and motive. Literal production units included character, setting, initiating event, problem identification, event, and resolution. These main points were used for the coding of the children narratives. In the supplemental materials, Table S2 provides an overview of the number of main points (for details, see Tables S4-S7). For each literal or inferential main point that was included in their narratives, children received one point. A second rater coded $20 \%$ of the narratives. Raters were blind to the treatment condition of the children. The intra-class correlation (ICC2) between first and second 
rater was calculated as a measure of interrater reliability. At all four measurement points, the interrater reliability was good for the inference score (pretest: $I C C 2=.97$; posttest: $I C C 2=.96$; first follow-up: $I C C 2=.96$; second follow-up: $I C C 2=.94)$. For the literal score, interrater reliability was also good at each measurement point (pretest: $I C C 2=.98$; posttest: $I C C 2=.95$; first follow-up: $I C C 2=.96$; second follow-up: $I C C 2=.94)$. Discrepancies between the raters were resolved through discussion.

Narrative comprehension. After completion of the narrative production task, children answered 10 narrative comprehension questions adapted from Paris and Paris (2003). For the pretest, we used an adaptation by Silva \& Cain (2015); for the first follow-up, we used an adaptation by Lepola and colleagues (2012). For the posttest and the second follow-up, we developed two new adaptations based on Paris and Paris (2003). The questions and coding schemes are provided in the supplemental materials. Five questions targeted inferential comprehension, and thus tapped implicit information that required inferencing (dialogue, feelings, thoughts, prediction, and theme). Five questions targeted literal comprehension, and thus tapped information explicitly stated in the picture book (characters, setting, initiating event, problem identification, and resolution). Answers were transcribed and scored on the basis of the coding scheme by Paris and Paris (2003). Children received one point if their answer contained the requested element (e.g., plausible thoughts). If the answer also contained an elaboration of the element (e.g., the cause of the thoughts), children received an additional point. To determine the interrater reliability (Cohen's kappa), a second rater scored 20\% of children's responses. At all four measurement points, the interrater reliability was good for the inferential comprehension items (pretest: $\kappa s=.68-.84$; posttest: $\kappa s=.72-.82$; first follow-up: $\kappa=.68-.79$; second followup: $\kappa s=.66-.93)$ and good for the literal comprehension items (pretest: $\kappa s=.72-.95$; posttest: $\kappa s$ 
$=.76-.96$; first follow-up: $\kappa s=.71-.87$; second follow-up: $\kappa \mathrm{s}=.68-.86$ ). Discrepancies between the raters were resolved through discussion.

\section{Vocabulary.}

Vocabulary breadth. To assess intervention effects on vocabulary breadth, we developed a picture naming task. Similar to the procedure reported by Lever and Sénéchal (2011), we selected 15 pictures from the wordless picture books that were used in the dialogic reading intervention. Each picture represented a familiar concept. Children were asked to name the objects by target words (see supplemental materials, Table S3). Target words were assumed to be unfamiliar to five-year-olds prior to the dialogic reading intervention because they were low in word frequency according to the childLex corpus (Schroeder, Würzner, Heister, Geyken \& Kliegl, 2015), normalized lemma frequency/million: $M=7.41(S D=6.32)$. If children did not produce the target word (e.g., igloo) but a similar word (e.g., "house"), they were asked to produce alternative labels for the object until they produced the target word or until they could not think of any more alternative labels. Children received one point for each target word and zero points for a similar word. Due to time constraints, the picture naming task was not administered at the first follow-up measurement point. The internal consistency was adequate (pretest: $\alpha=.71$; posttest: $\alpha=.76$; second follow-up: $\alpha=.75$ ).

Vocabulary depth. Children completed a standardized test of vocabulary depth in which they were asked to explain 14 concepts (vocabulary subtest of the German Wechsler Preschool and Primary Scale of Intelligence; Petermann, 2009). Children received up to two points for each item. Answers were scored according to the test manual. Two points were awarded for one or two essential semantic features, or at least two important, but not essential semantic features that demonstrated that the child had a comprehensive understanding of the concept. One point was 
awarded for an important, but not essential semantic feature, or for an appropriate example that demonstrated that the child had a proper, but not comprehensive understanding of the concept. The reported split-half reliability is $\operatorname{good}(r=.88)$.

\section{Control variables.}

Storybook exposure. To assess the amount of storybook exposure prior to the dialogic reading intervention, children completed an auditory version of the title recognition test for preschoolers (TRT; Grolig, Cohrdes, \& Schroeder, 2017), which is an adaptation of the title recognition test by Sénéchal, LeFevre, and Lawson (1996). The TRT consists of 20 real titles and 10 foils. Children indicated via computer button press whether they recognized a title. A corrected score was computed by subtracting the proportion of selected foils from the proportion of selected titles. None of the books used in the TRT was used for the vocabulary breadth task or in the dialogic reading intervention. In this sample, the corrected score varied considerably $(\mathrm{M}=$ $.37, \mathrm{SD}=.21)$. Children recognized on average about eight titles (range: zero to 20 titles). The internal consistency was acceptable $(\alpha=.68)$.

Nonverbal IQ. The raw scores of the subtests Classifications, Matrices, and Completing Sequences from the Culture Fair Intelligence Test (CFT 1-R; German version: Weiß \& Osterland, 2013) were added to form a single scale. Age-standardized scores were used in all analyses. In this sample, the average standardized nonverbal IQ, $M=48.6(S D=5.7)$, was similar to the mean norm score, $M=50(S D=10)$. The reported re-test reliability of the combined subtests is good $(r=.94)$.

Verbal short-term memory. Children completed a standardized digit span forward test (BUEVA; Esser, 2002). Age-standardized scores were used in all analyses. In this sample, the 
average standardized verbal short-term memory, $M=49.9(S D=8.3)$, was similar to the mean norm score, $M=50(S D=10)$. The reported re-test reliability is good $(r=.90)$.

\section{Treatment Fidelity}

To ensure that the dialogic reading intervention and the alternative intervention were implemented as planned, each intervention followed a manual. The manual of the dialogic reading intervention prescribed the sequence in which the books were used and included scripted questions about target vocabulary, literal narrative comprehension, and inferential narrative comprehension. To assess treatment fidelity, instructors completed a short questionnaire directly after each of the 42 sessions. In line with early literacy research (e.g., Guo et al., 2016), we assessed adherence to the intervention program on the group level $(5=$ very good, $4=$ good, $3=$ satisfactory, 2 = unsatisfactory, 1 = poor), dosage (number of sessions attended by each child), and participant responsiveness on the individual level (quantity and quality of child involvement in the program: $5=$ very good, $4=$ good, $3=$ satisfactory, $2=$ unsatisfactory, $1=$ poor . Adherence to the intervention program was good (dialogic reading: $M=4.5, S D=0.3$; alternative treatment: $M=3.9, S D=0.9)$. On average, children attended $33.9(81 \%)$ of the 42 sessions (dialogic reading: $M=34.4, S D=3.8$; alternative treatment: $M=33.6, S D=5.3$ ). All books used in the 42 dialogic reading sessions contained target vocabulary. By contrast, only in 36 of the 42 dialogic reading sessions, narrative comprehension questions were asked. Thus, the effective mean treatment exposure to narrative comprehension questions during dialogic reading was 9 hours and 45 minutes whereas the effective mean treatment exposure to vocabulary during dialogic reading was 11 hours and 30 minutes. Participant responsiveness was good regarding involvement quantity (dialogic reading: $M=4.1, S D=0.4$; alternative treatment: $M=4.2, S D=$ 
0.4 ) and involvement quality (dialogic reading: $M=4.3, S D=0.3$; alternative treatment: $M=$ 4.1, $S D=0.5)$.

\section{Statistical Analysis}

All analyses were conducted with the software $R$ (R Core Team, 2017). Due to technical problems or illnesses, there were a few missing data values in the oral language variables at each measurement point (pretest: 1.3\%; posttest: 2.2\%; first follow-up: 2.5\%; second follow-up: 4.1\%; see Table 1). Measurement points were nested in children, and children were nested in child care groups. We fitted 3-level hierarchical linear models (Raudenbush \& Bryk, 2002) with children and child care group as random effects. The models included treatment, time, and their interaction as fixed effects. We controlled for storybook exposure, nonverbal IQ, and verbal short-term memory in all models. The categorical variables treatment and time were effectcoded. To reduce nonessential multicollinearity, the continuous variables storybook exposure, nonverbal IQ, and verbal short-term memory were centered.

Models were estimated with the lmer function of the $R$ package lme4 (Bates, Maechler, Bolker, \& Walker, 2015). Effects were tested by using the Anova function of the car package (type 3 model comparisons; Fox \& Weisberg, 2011). Significant interactions between treatment and time were explored by first testing the simple main effect of treatment (Fox \& Weisberg, 2011) at each measurement point. If the simple main effect of treatment was significant at a measurement point, this effect was further explored using post hoc comparisons between treatments, for which we applied the glht function of the multcomp package (Hothorn, Bretz, \& Westfall, 2008) by using cell means coding and single degree-of-freedom contrasts. Effect sizes that are based on standard deviations (e.g., Cohen's $d$ ) are often not informative for practical considerations (Wasik et al., 2016). Consequently, we report absolute differences $(\Delta)$ 
inproportion correct estimates as effect size measure. This allows us to compare the magnitude of effects between different language measures. Finally, to assess the fit of the models, we estimated the variance explained by fixed effects (marginal $R_{2}$ ) and the variance explained by fixed effects and random effects (conditional $R_{2}$ ) as reported in Nakagawa and Schielzeth (2012) by using the r.squaredGLMM function of the MuMIn package (Bartón, 2017).

\section{Results}

\section{Descriptive Results}

Table 1 summarizes the results of the oral language outcome variables at the four measurement points. Children's vocabulary skills increased considerably between pretest and second follow-up. For example, at pretest, children mentioned on average about $50 \%$ of the semantic features of target vocabulary, and they labelled on average $33 \%$ of low frequency words correctly. By contrast, at second follow-up, they mentioned on average about $70 \%$ of the semantic features of target vocabulary, and they labelled on average $66 \%$ of low frequency words correctly.

\section{Treatment Effects}

We investigated the effects of the dialogic reading intervention on the development of oral language skills by fitting a hierarchical linear model for each of the six language variables. Preliminary analyses showed that all interaction terms between treatment and control variables were not significant and are therefore not reported in the final models, which are summarized in Table 2. The fixed effects in the models explained a substantial amount of variance in narrative and vocabulary skills (between $18 \%$ and $39 \%$ ). The random effects also explained a substantial amount of variance. The variation between children within a child care group was more pronounced than the variation between children from different child care groups (see Table 2). 
Table 1

Descriptive Statistics for Language Outcome Measures by Treatment and Measurement Point

\begin{tabular}{|c|c|c|c|c|c|c|c|c|c|c|c|c|}
\hline \multirow[b]{2}{*}{ Treatment } & \multicolumn{3}{|c|}{ Pretest } & \multicolumn{3}{|c|}{ Posttest } & \multicolumn{3}{|c|}{ Follow-Up I } & \multicolumn{3}{|c|}{ Follow-Up II } \\
\hline & $M$ & $(S D)$ & $n$ & $M$ & $(S D)$ & $n$ & $M$ & $(S D)$ & $n$ & $M$ & $(S D)$ & $n$ \\
\hline & \multicolumn{12}{|c|}{ Inferential narrative comprehension } \\
\hline Dialogic reading & .46 & $(.19)$ & 68 & .69 & $(.22)$ & 66 & .68 & $(.19)$ & 57 & .78 & $(.18)$ & 48 \\
\hline Alternative treatment & .47 & $(.18)$ & 64 & .54 & $(.18)$ & 60 & .54 & $(.16)$ & 39 & .72 & $(.17)$ & 35 \\
\hline \multirow[t]{2}{*}{ No treatment } & .47 & $(.17)$ & 65 & .54 & $(.23)$ & 60 & .57 & $(.16)$ & 46 & .78 & $(.15)$ & 41 \\
\hline & \multicolumn{12}{|c|}{ Literal narrative comprehension } \\
\hline Dialogic reading & .52 & $(.22)$ & 68 & .73 & $(.17)$ & 65 & .73 & $(.18)$ & 53 & .81 & $(.13)$ & 50 \\
\hline Alternative treatment & .56 & $(.21)$ & 64 & .60 & $(.21)$ & 61 & .61 & $(.15)$ & 40 & .76 & $(.14)$ & 35 \\
\hline \multirow[t]{2}{*}{ No treatment } & .49 & $(.23)$ & 65 & .63 & $(.23)$ & 60 & .63 & $(.18)$ & 47 & .79 & $(.11)$ & 41 \\
\hline & \multicolumn{12}{|c|}{ Inferential narrative production } \\
\hline Dialogic reading & .27 & $(.15)$ & 68 & .40 & $(.16)$ & 66 & .39 & $(.14)$ & 56 & .45 & $(.15)$ & 53 \\
\hline Alternative treatment & .27 & $(.15)$ & 64 & .38 & $(.18)$ & 62 & .38 & $(.17)$ & 40 & .48 & $(.19)$ & 35 \\
\hline \multirow[t]{2}{*}{ No treatment } & .23 & $(.16)$ & 65 & .36 & $(.18)$ & 60 & .38 & $(.16)$ & 47 & .47 & $(.15)$ & 41 \\
\hline & \multicolumn{12}{|c|}{ Literal narrative production } \\
\hline Dialogic reading & .44 & $(.16)$ & 68 & .53 & $(.16)$ & 66 & .54 & $(.17)$ & 56 & .69 & $(.14)$ & 53 \\
\hline Alternative treatment & .44 & $(.14)$ & 64 & .52 & $(.16)$ & 62 & .54 & $(.14)$ & 40 & .64 & $(.13)$ & 35 \\
\hline \multirow[t]{2}{*}{ No treatment } & .38 & $(.17)$ & 65 & .48 & $(.15)$ & 60 & .55 & $(.17)$ & 47 & .63 & $(.09)$ & 41 \\
\hline & \multicolumn{12}{|c|}{ Vocabulary depth } \\
\hline Dialogic reading & .45 & $(.19)$ & 69 & .53 & $(.18)$ & 67 & .61 & $(.16)$ & 58 & .68 & $(.15)$ & 56 \\
\hline Alternative treatment & .49 & $(.18)$ & 66 & .46 & $(.16)$ & 64 & .59 & (.13) & 41 & .68 & (.13) & 37 \\
\hline \multirow[t]{2}{*}{ No treatment } & .47 & $(.18)$ & 66 & .48 & $(.20)$ & 61 & .61 & $(.17)$ & 47 & .68 & $(.16)$ & 41 \\
\hline & \multicolumn{12}{|c|}{ Vocabulary breadth } \\
\hline Dialogic reading & .32 & $(.19)$ & 69 & .56 & $(.19)$ & 67 & & & & .60 & $(.22)$ & 56 \\
\hline Alternative treatment & .29 & $(.19)$ & 66 & .38 & $(.20)$ & 64 & & N/A & & .56 & $(.19)$ & 38 \\
\hline No treatment & .29 & $(.20)$ & 66 & .39 & $(.23)$ & 62 & & & & .54 & (.19) & 41 \\
\hline
\end{tabular}

Note. Proportion correct scores are displayed. Vocabulary breadth data were not collected at follow-up I. 
Table 2

Hierarchical Linear Models of Language Outcomes with Treatment, Time, their Interaction, and Control Variables as Fixed Effects and Child Care Group and Children as Random Intercepts

\begin{tabular}{|c|c|c|c|c|c|c|c|c|c|c|c|c|c|}
\hline & \multirow[b]{3}{*}{$d f$} & \multicolumn{4}{|c|}{ Narrative comprehension } & \multicolumn{4}{|c|}{ Narrative production } & \multicolumn{4}{|c|}{ Vocabulary } \\
\hline & & \multicolumn{2}{|c|}{ Inferential } & \multicolumn{2}{|c|}{ Literal } & \multicolumn{2}{|c|}{ Inferential } & \multicolumn{2}{|c|}{ Literal } & \multicolumn{2}{|c|}{ Depth } & \multicolumn{2}{|c|}{ Breadth } \\
\hline & & $\chi^{2}$ & $p$ & $\chi^{2}$ & $p$ & $\chi^{2}$ & $p$ & $\chi^{2}$ & $p$ & $\chi^{2}$ & $p$ & $\chi^{2}$ & $p$ \\
\hline \multicolumn{14}{|l|}{ Fixed effects } \\
\hline Intercept & 1 & $2,362.46$ & $<.001$ & $4,733.88$ & $<.001$ & $1,262.93$ & $<.001$ & $3,019.50$ & $<.001$ & $1,547.58$ & $<.001$ & 756.28 & $<.001$ \\
\hline \multicolumn{14}{|l|}{ Experimental variables } \\
\hline Treatment & 2 & 10.13 & $<.01$ & 7.05 & .03 & 0.82 & .66 & 3.25 & .20 & 0.16 & .92 & 6.53 & .04 \\
\hline Time & 3 & 221.62 & $<.001$ & 172.50 & $<.001$ & 153.81 & $<.001$ & 206.95 & $<.001$ & 280.69 & $<.001$ & 343.61 & $<.001$ \\
\hline Treatment $\mathrm{x}$ Time & 6 & 32.76 & $<.001$ & 16.08 & .01 & 4.00 & .68 & 7.48 & .28 & 16.22 & $<.01$ & 38.21 & $<.001$ \\
\hline \multicolumn{14}{|l|}{ Control variables } \\
\hline Storybook exposure & 1 & 6.01 & .01 & 7.09 & $<.01$ & 0.05 & .82 & 8.00 & $<.01$ & 12.67 & $<.01$ & 42.31 & $<.001$ \\
\hline Verbal STM & 1 & 1.14 & .28 & 1.88 & .17 & 0.18 & .67 & 1.02 & .31 & 5.95 & .02 & 38.21 & $<.001$ \\
\hline Nonverbal IQ & 1 & 4.45 & .03 & 3.05 & .08 & 2.15 & .14 & 5.78 & .01 & 5.42 & .02 & 0.40 & .53 \\
\hline \multicolumn{14}{|l|}{ Random effects } \\
\hline Children & 1 & 22.92 & $<.001$ & 5.77 & .02 & 12.63 & $<.01$ & 23.52 & $<.001$ & 141.55 & $<.001$ & 123.72 & $<.001$ \\
\hline Child care groups & 1 & 3.02 & .08 & 0.10 & .75 & 6.44 & .01 & 4.38 & .04 & 10.11 & $<.01$ & 5.84 & .02 \\
\hline Marginal $R_{2}$ & & \multicolumn{2}{|c|}{.30} & \multicolumn{2}{|c|}{.26} & \multicolumn{2}{|c|}{.18} & \multicolumn{2}{|c|}{.27} & \multicolumn{2}{|c|}{.27} & \multicolumn{2}{|c|}{.39} \\
\hline Conditional $R_{2}$ & & \multicolumn{2}{|c|}{.46} & \multicolumn{2}{|c|}{.34} & \multicolumn{2}{|c|}{.33} & \multicolumn{2}{|c|}{.43} & \multicolumn{2}{|c|}{.67} & \multicolumn{2}{|c|}{.76} \\
\hline
\end{tabular}

Note. STM, Short-term memory. Tests are based on Type III sum of squares and $\chi^{2}$ values with Kenward-Roger $d f$. 
- Dialogic Reading $\square$ Alternative Treatment $\square$ No Treatment

\section{Narrative Comprehension}

a.
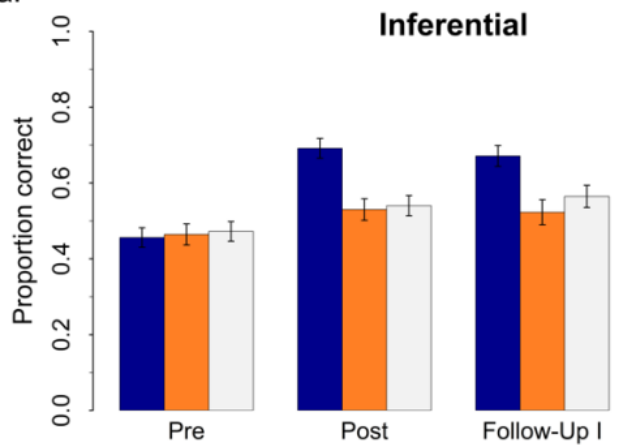

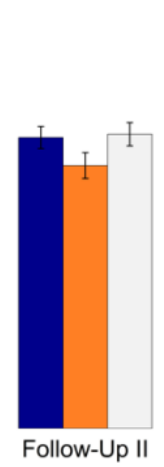

b
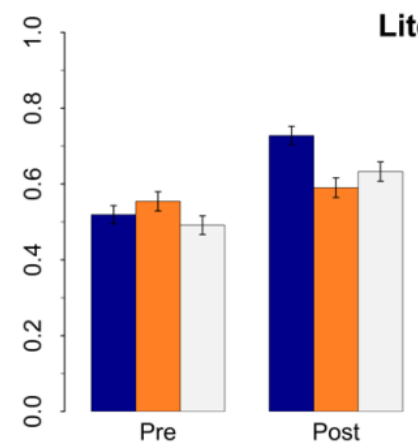

Literal
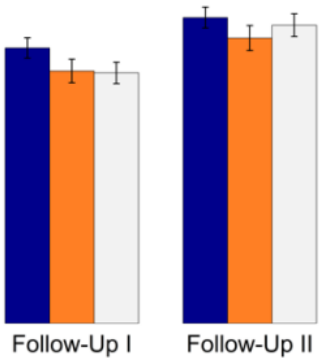

\section{Narrative Production}

c.

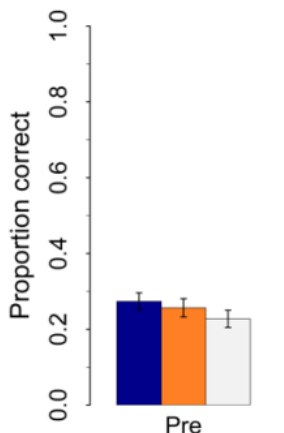

Inferential
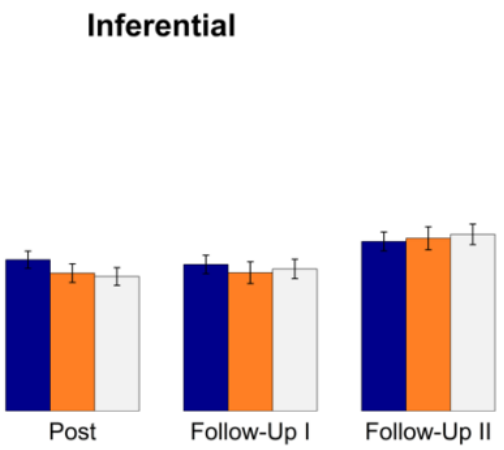

d.
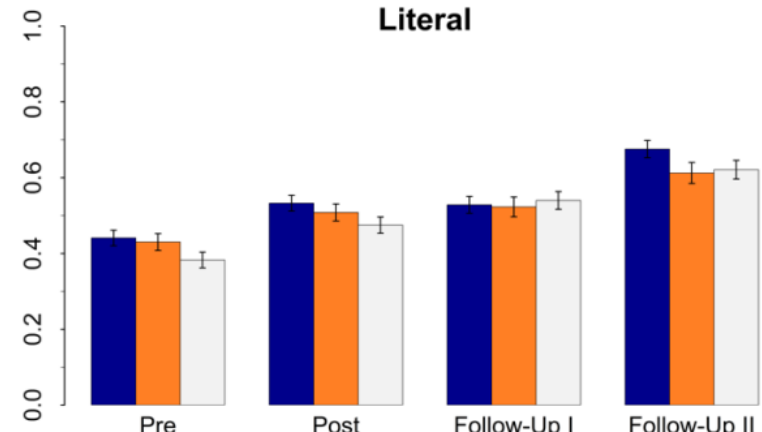

\section{Vocabulary}
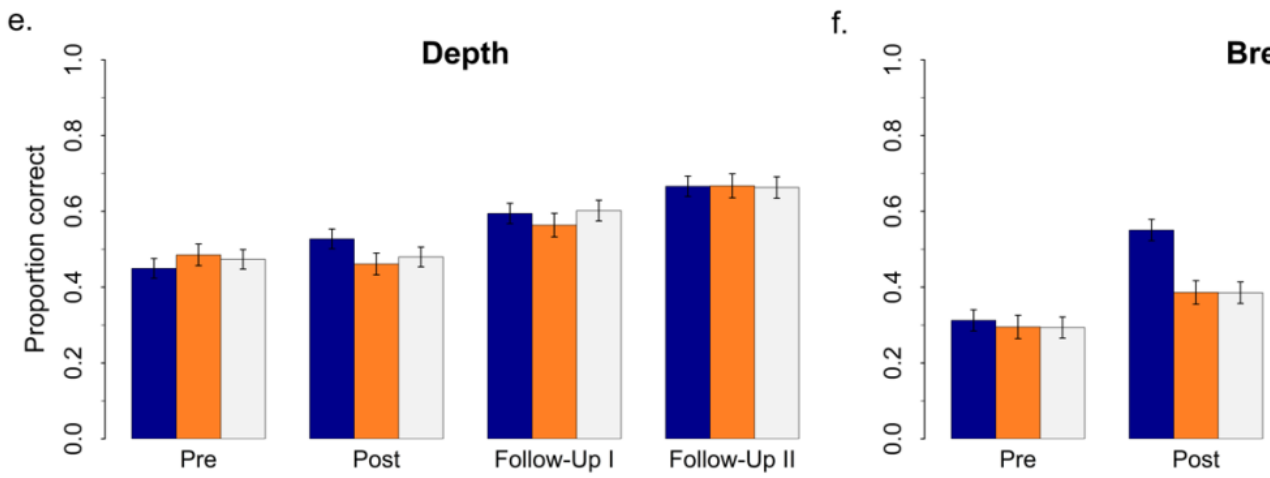

Breadth

N/A

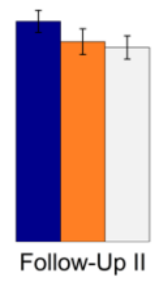

Figure 1. Mean proportion correct estimates in narrative and vocabulary skills by treatment and measurement point. Error bars show standard errors. 
Figure 1 shows the models' estimates for each treatment at the four measurement points. To analyze the effects of the dialogic reading intervention, we explored significant interactions between treatment groups and time by using post hoc contrasts. We tested whether treatment groups (dialogic reading, alternative treatment, no treatment) differed at pretest, posttest, first follow-up, and second follow-up.

Inferential narrative comprehension. There were significant main effects of time and treatment, and the interaction between treatment and time was also significant (see Table 2 and Figure 1a). The simple main effect of treatment was not significant at pretest, $\chi^{2}(2)=0.15, p=$ .93 , but significant at posttest, $\chi_{2}(2)=23.30, p<.001$. At posttest, dialogic reading outperformed alternative treatment $(\Delta=16 \%, t=4.14, p<.001)$ and no treatment condition $(\Delta=$ $16 \%, t=4.15, p<.001)$. Alternative treatment and no treatment condition did not differ at posttest $(\Delta=0 \%, t=-0.10, p=.92)$. At first follow up, the simple main effect of treatment was significant, $\chi^{2}(2)=13.67, p<.01$, with the same results pattern as for posttest: Dialogic reading outperformed alternative treatment $(\Delta=15 \%, t=3.44, p<.001)$ and no treatment condition $(\Delta=$ $11 \%, t=2.73, p<.01)$. Alternative treatment and no treatment condition did not differ at first follow-up $(\Delta=-4 \%, t=-0.85, p=.39)$. The simple main effect of treatment was not significant at second follow-up, $\chi^{2}(2)=3.56, p=.17$.

At posttest, children in the dialogic reading group made between one and two inferences more than children in the comparison groups, who made about five out of ten inferences. Between posttest and first follow-up, the dialogic reading group maintained its advantage over the comparison groups. At second follow-up, the comparison groups had caught up with the dialogic reading group. In sum, the results indicate that dialogic reading had a positive effect on inferential comprehension skills that was maintained five months after the posttest. 
Literal narrative comprehension. There was a significant main effect of time, and the interaction between treatment and time was also significant (see Table 2 and Figure 1b). Post hoc comparisons showed that the simple main effect of treatment was not significant at pretest, $\chi_{2}^{2}(2)$ $=2.73, p=.16$. By contrast, the simple main effect of treatment was significant at posttest, $\chi^{2}(2)$ $=14.52, p<.001$. At posttest, dialogic reading outperformed alternative treatment $(\Delta=13 \%, t=$ $3.69, p<.001)$ and no treatment condition $(\Delta=9 \%, t=2.62, p<.01)$. Alternative treatment and no treatment condition did not differ at posttest $(\Delta=-4 \%, t=-1.06, p=.29)$. Further, the simple main effect of treatment was not significant at first follow up, $\chi^{2}(2)=3.75, p=.15$, and at second follow-up, $\chi_{2}(2)=2.72, p=.26$.

At posttest, children in the dialogic reading group included on average one literal comprehension aspect more than children the comparison groups, who included on average six out of ten literal comprehension aspects. At first follow-up, the comparison groups had caught up with the dialogic reading group. In sum, the results indicate that dialogic reading had a shortterm effect on literal comprehension skills.

Inferential narrative production. There was a significant main effect of time, but no significant interaction between treatment and time (see Table 2 and Figure 1c). This indicates that dialogic reading did not have an effect on the proportion of inferential main points included in the story.

Literal narrative production. There was a significant main effect of time, but no significant interaction between treatment and time (see Table 2 and Figure 1d). This indicates that dialogic reading did not have an effect on the proportion of literal main points included in the story. 
Vocabulary depth. There was a significant main effect of time and a significant interaction between treatment and time (see Table 2 and Figure 1e). Post hoc comparisons showed that the simple main effect of treatment was not significant at pretest, $\chi^{2}(2)=0.90, p=$ .64 , at posttest, $\chi_{2}(2)=4.28, p=.12$, at first follow up, $\chi^{2}(2)=0.75, p=.69$, and at second follow-up, $\chi^{2}(2)=0.34, p=.84$. Thus, none of the simple main effects of treatment were significant. As the omnibus interaction effect between treatment and time was significant and the simple main effect of treatment approached significance at posttest, we investigated the nature of this interaction by comparing the pretest-posttest change in scores between treatment groups. Dialogic reading showed a stronger growth than alternative treatment $(\Delta=10 \%, t=3.73, p<$ $.001)$ and no treatment condition $(\Delta=7 \%, t=2.61, p<.01)$. Growth did not differ between alternative treatment and no treatment condition $(\Delta=3 \%, t=1.08, p=.28)$.

Between pretest and posttest, the dialogic reading group learned on average one word definition more than the comparison groups, which produced on average between six and seven out of 14 word definitions. At first follow-up, the comparison groups had caught up with the dialogic reading group. In sum, the results indicate that dialogic reading had a short-term effect on vocabulary depth.

Vocabulary breadth. There were significant main effects of time and treatment, and the interaction between treatment and time was also significant (see Table 2 and Figure 1f). Post hoc comparisons showed that the simple main effect of treatment was not significant at pretest, $\chi^{2}(2)$ $=1.78, p=.41$. By contrast, the simple main effect of treatment was significant at posttest, $\chi^{2}(2)$ $=22.25, p<.001$. Dialogic reading outperformed alternative treatment $(\Delta=16 \%, t=3.93, p<$ $.001)$ and no treatment condition $(\Delta=17 \%, t=4.15, p<.001)$ at posttest. Alternative treatment 
and no treatment condition did not differ at posttest $(\Delta=0 \%, t=0.02, p=.99)$. At second follow-up, the simple main effect of treatment was not significant, $\chi^{2}(2)=2.93, p=.23$.

Overall, the dialogic reading group learned low frequency words faster than the children in the comparison groups. At posttest, children in the dialogic reading group knew on average three low frequency words more than children in comparison groups, who knew on average between five and six out of 15 low frequency words. The comparison groups caught up with the dialogic reading group between posttest and second follow-up. In sum, the results indicate that dialogic reading had a short-term effect on vocabulary breadth.

Altogether, the analyses showed that dialogic reading was effective in promoting many of the targeted language skills, including inferential narrative comprehension, literal narrative comprehension, vocabulary depth, and vocabulary breadth, but not narrative production skills. The treatment groups did not differ in oral language skills at pretest, and the dialogic reading group showed a stronger growth in the narrative comprehension and vocabulary measures than both comparison groups during the last preschool year. At the beginning of grade 1, the dialogic reading group still outperformed the comparison groups in inferential narrative comprehension, indicating that the positive effect on this skill was maintained five months after the posttest.

More specifically, at posttest, the difference between the dialogic reading group and the comparison groups was slightly higher for inferential narrative comprehension (about 16\%) than for literal narrative comprehension (about 11\%). Moreover, the difference between the dialogic reading group and the comparison groups was higher for vocabulary breadth (about 16\%) than for vocabulary depth (about 8\%) at posttest. At first follow-up, the difference between dialogic reading group and comparisons groups in inferential narrative comprehension (about 13\%) were similar to this difference at posttest (about 16\%). Thus, dialogic reading was more effective in 
supporting the development of inferential comprehension skills and vocabulary breadth than literal comprehension skills and vocabulary depth.

\section{Discussion}

This study investigated the impact of narrative dialogic reading with mostly wordless picture books on oral language skills in comparison to an alternative treatment group and a no treatment group. Narrative dialogic reading had positive effects on inferential and literal narrative comprehension skills during the last year before school entry. The effect on inferential narrative comprehension was stronger than the effect on literal narrative comprehension. Overall, effects on narrative comprehension were stronger than the impact on narrative production skills, which was not significant. Dialogic reading also benefitted the growth of vocabulary breadth and depth during the last preschool year. The effect on vocabulary breadth was stronger than the effect on vocabulary depth. At the beginning of first grade, the comparison groups had caught up with the dialogic reading group in the narrative comprehension and vocabulary skills, with one exception: The dialogic reading group still outperformed the comparison groups in inferential narrative comprehension. The comparison groups caught up by the end of first grade. In comparison to other dialogic reading interventions (e.g., Whitehurst et al., 1994; Zevenbergen et al., 2003), which lasted for up to 38 hours over one school year, the potential treatment dosage in our study was only 14 hours, and the mean effective treatment dosage was 9 hours and 45 minutes for narrative comprehension and 11 hours and 30 minutes for vocabulary. This intervention dose had small short-term effects on narrative comprehension and vocabulary skills.

\section{Effects on Narrative Skills}

Inferential and literal narrative comprehension skills both benefitted from dialogic

reading. The effect on narrative comprehension skills in this study had the same magnitude as the 
effect in a previous study (van Kleeck et al., 2006), indicating that children with typically developing language skills benefit from this approach to the same degree as children with a language impairment. In the present study, the effect on inferential narrative comprehension was slightly stronger than the effect on literal narrative comprehension. By contrast, the previous study found that literal and inferential skills benefitted equally from dialogic reading (van Kleeck et al., 2006). This discrepancy is likely due to the amount of inferential and literal questions that were asked in the respective interventions. Our intervention used the same amount of inferential and literal comprehension questions (50\% of each type), whereas, in the previous study, only $30 \%$ of the questions were inferential, and $70 \%$ were literal (van Kleeck et al., 2006). The higher proportion of inferential questions in this study's intervention plausibly explains why we found a stronger effect on inferential skills than on literal skills. Possibly, the use of wordless picture books also contributed to inferential comprehension learning by facilitating children's inferential activities in comparison to storybooks with text, which were used by van Kleeck and colleagues (2006).

Five months after posttest, the effect on inferential narrative comprehension was maintained. This indicates that children in the dialogic reading group used narrative knowledge that they had acquired through the intervention in the narrative comprehension task. Importantly, different stories were used at the first follow-up measurement and at the posttest. Therefore, the maintenance of the effect was not due to some selective memory effect in the dialogic reading group: Children applied their narrative knowledge to similar, but new narrative contents. In contrast, the advantage in literal narrative comprehension was not maintained. Parents generally ask more questions about explicit story contents than questions about implicit story contents (Huebner \& Meltzoff, 2005; van Kleeck et al., 1997). Therefore, the comparison groups probably 
acquired literal narrative comprehension faster than inferential narrative comprehension through shared reading at home. Taken together, the results suggest that the intervention provided unique learning opportunities for inferential skills that were not provided to the same extent by shared reading at home. Dialogic reading was effective in fostering cognitive skills that contribute substantially to children's later reading comprehension (Silva \& Cain, 2015).

Previous intervention studies have found a positive effect of dialogic reading on narrative production skills (Lever \& Sénéchal, 2011; Zevenbergen et al., 2003). Contrary to expectation, our intervention had no effect on narrative production skills, which can be explained by several reasons. First, the present study investigated whether actively involving children in producing narratives and answering comprehension questions would improve their ability to communicate the main points in their narratives, which would have been a transfer effect. Transfer effects of shared reading interventions are often smaller than effects on specifically targeted skills (e.g., Mol et al., 2009). Our intervention targeted narrative comprehension skills through specific, standardized questions. Thus, facilitating the production of narrative main points was not the focus of the dialogic reading intervention. Regarding that the effects on narrative comprehension were small, it is not surprising that we did not find transfer effects on narrative production.

Second, the narrative production task was particularly demanding for young children because they produced a narration based on a sequence of pictures, without any oral narrative being provided by an adult. By contrast, retelling tasks are far less demanding because the children first hear an oral narrative from an adult and then reproduce this narrative with the aid of picture prompts (e.g., Lever \& Sénéchal, 2011). Possibly, a retelling task instead of a story production task would have been more sensitive for assessing differences in narrative production skills between treatment groups. 
Third, whereas basic dialogic reading questions were asked by the trainers during the intervention to stimulate the oral production of the children, these questions were not asked during the assessment of narrative production skills for standardization reasons. The assessment was conducted in a one-on-one situation in which the experimenter did not participate in the narration because the aim was to assess children's narrative production skills. Therefore, children received much less feedback on their narration than during the intervention, which could have decreased their narrative production performance during the assessment in comparison to the intervention group situation. Considering that narration is inherently social, new forms of narrative assessment could use joint narration of children groups or dyads (e.g., parent and child) as a unit for analyzing intervention effects.

Crucially, the intervention in this study highlighted the importance of story grammar elements through narrative comprehension questions implicitly. Story grammar elements were not explicitly introduced as building blocks that should be used in telling stories. This strategy apparently did not benefit narrative production, which places greater demands on children's ability to structure story elements than narrative comprehension. Engaging children in narrative extratextual talk by asking comprehension questions may not be sufficient for changing the narrative schemata that underlie children's narrations. By contrast, our results suggest that positive effects of narrative comprehension questions on subsequent narrative production reported by experimental studies were probably due to an attention-guiding function of questions (Silva et al., 2017; Silva \& Cain, 2014; see Lenhart, Lenhard, Vaahtoranta, \& Suggate, 2019, for a discussion of the attention-guiding function of questions regarding vocabulary acquistion). Teaching story grammar by explicitly introducing, labelling and applying story categories could help preschoolers to produce better narratives. This notion is supported by a study with first 
graders in which explicit story grammar instruction improved both narrative comprehension and production skills (Paris \& Paris, 2007). In conclusion, using picture books with a clear story line is apparently a necessary, but not sufficient condition for achieving an effect on narrative production skills. Using both implicit and explicit instruction strategies could support the development of both narrative comprehension and narrative production skills in preschool.

\section{Effects on Vocabulary Skills}

Vocabulary breadth and vocabulary depth increased through dialogic reading. After six months, children had learned on average three out of 15 targeted, low frequency words. In comparison, in a dialogic reading intervention with small groups that lasted for two months, children learned on average one out of 16 targeted words (Lever \& Sénéchal, 2011). Thus, effects on vocabulary breadth are similar between the studies if we take into account the different durations of the interventions. Importantly, even though adding scripted narrative comprehension questions changed the intervention focus and reduced the time available for extratextual talk about vocabulary, this did not prevent the children from learning new words in this study.

Other than expected, the effect on vocabulary breadth was stronger than the effect on vocabulary depth, even though the intervention targeted both skills equally. Experimental studies found that explaining word meanings during storybook reading to kindergarteners, as practiced in our intervention, leads to larger gains in their vocabulary breadth than vocabulary depth (Coyne, McCoach, Loftus, Zipoli, \& Kapp, 2009; Damhuis, Segers, \& Verhoeven, 2015). Our results suggest that narrative dialogic reading with wordless picture books is particularly suitable for teaching vocabulary breadth. To achieve stronger effects on vocabulary depth, children apparently need an extended vocabulary instruction (Coyne et al., 2009). 
By the beginning of first grade, children in the comparison groups had caught up with the dialogic reading group. The results (see Figure 1) show that the dialogic reading group did not fall back in any oral language skill, but that the comparison groups were fast in catching up with them. This finding is in line with a dialogic reading study that found no maintenance of effects in a middle class sample (Sim et al., 2014). By contrast, intervention effects on vocabulary were maintained one year after a Head Start intervention with a low-income sample (Whitehurst et al., 1999). Parents with a higher socioeconomic status often engage in more early literacy activities with their children before school entry than parents with a lower socioeconomic status (Sénéchal et al., 1996). Thus, the advantage of the dialogic reading group over the comparison groups was presumably short-lived because shared reading at home also had a strong influence on their development.

\section{Implications, Limitations, and Conclusions}

Most effects of the low-dose intervention did not outlast the posttest, which brings up the question what amount of dialogic reading would be needed to produce more sustainable effects. According to a large survey, child care workers read on average twice a day to preschoolers for about 15 minutes, which sums up to about 90 hours of shared reading in one academic year, of which about 72 hours are spend with fiction books (Wirts, Egert, \& Reber, 2017). In our study, the mean effective treatment dosage for narrative comprehension was 9.75 hours (11.5. hours for vocabulary), which is about $14 \%(16 \%)$ of the time child care workers usually spend on average reading fiction books with preschoolers (Wirts et al., 2017). To achieve substantial long-term effects, narrative dialogic reading would need to be implemented with a higher frequency and possibly a time span of two or more years (Noble et al., 2019), as was demonstrated by long-term developmental studies investigating the relation between shared reading and oral language 
development (e.g., DeBaryshe, 1993; Farrant \& Zubrick, 2013). To attain additional effects on narrative production, explicit instruction strategies could be used in addition to implicit narrative instruction (Paris \& Paris, 2007).

The intervention effects were not moderated by children's storybook exposure outside the intervention, or verbal short-term memory, or nonverbal intelligence. This indicates that the intervention was equally effective for all children regardless of their storybook exposure or cognitive abilities. Even though the intervention included high demand questions and targeted higher level language skills such as inferential and literal narrative comprehension, the benefit for children did not depend on prior experiences with shared book reading, indicating that narrative dialogic reading with wordless books is a low-threshold intervention.

On a theoretical level, our results shed new light on the learning mechanisms that underlie dialogic reading. The effects of narrative dialogic reading with wordless picture books on vocabulary skills had a similar magnitude as the reported effects of dialogic reading with textbased storybooks (Mol et al., 2009). This result supports the notion that learning through conversation and discussion could be the main learning mechanism behind dialogic reading, whereas the exposure to specific linguistic features of the text in children's books might be of secondary importance for vocabulary learning. To date, it is unclear which components of dialogic reading are most effective in promoting oral language skills, and there is a lack of research on the role of different book types regarding the magnitude and sustainability of the intervention effects (Zevenbergen \& Whitehurst, 2003). Future studies should investigate this question by comparing effects of dialogic reading interventions with wordless picture books versus the same picture books with some pictures replaced by text passages. Additionally, from the perspective of a triad model of shared reading in which oral language learning through shared 
reading originates from a triangular interplay between adult, child, and book (Fletcher \& Reese, 2005; van Kleeck, 2003), our results suggest that a more direct interaction of children with wordless picture books can be similarly effective as children's interaction with text-based storybooks, which is (at least partly) mediated through adults' decoding skills.

The present study has several limitations. First, the focus of this study was to evaluate the impact of a narrative dialogic reading intervention on preschoolers' oral language skills. Regarding developmental effects, data about narrative skills should be interpreted with caution. Even though the same set of questions was used at each measurement point, we did not counterbalance the four picture books. Thus, it is possible that differences in narrative skills between measurement points are not only due to developmental trends, but also due to slight differences between the picture books used. To allow strong developmental interpretations, future studies could counterbalance picture books and measurement points. Second, children were randomly assigned to a treatment group on the child care center level. Thus, condition assignment was not entirely random on the child level. As this randomization procedure is not optimal regarding sampling error, we controlled for the dependency of observations within clusters by using hierarchical linear models with both child and child care group as random effects. Future studies should assign children individually to a treatment. Third, the children in this study had already acquired age-adequate oral language skills prior to intervention, which potentially diminished the effects of our intervention. Future studies should investigate whether children with under-average oral language skills benefit to a similar or even higher degree from a narrative dialogic reading intervention. Fourth, even though the dialogic reading intervention activities and the 20 minutes book sessions at the child care centers were similar to regular shared reading activities in kindergarten groups, the intervention was conducted by research 
assistants, which reduces the ecological validity of our findings. In future studies, child care workers should be trained as instructors to maximize the ecological validity. Fifth, our intervention was not effective in promoting narrative production skills. Adding intervention elements for explicitly teaching story grammar could be more effective in promoting preschooler's narrative production skills. Future studies could implement such explicit strategies to see whether they are effective with preschool children. In particular, future studies could compare the effects of traditional dialogic reading versus narrative dialogic reading with wordless picture books to evaluate their respective effects on children's oral language. Moreover, future studies could investigate how informational books could be used for fostering children's oral language skills through dialogic reading (e.g. Bergman Deitcher, Aram, \& Johnson, 2018). Sixth, due to frequent questions about figures' inner states, it is possible that our intervention also had effects in non-language domains such as socio-emotional development (e.g., social imagination; Lysaker \& Miller, 2011) and visual literacy (Arizpe, 2013), which could be investigated by future studies. Seventh, the reliability of the measures used in the present study was good, with the exception of the title recognition test's internal consistency, which was slightly lower than what is conventionally deemed to be acceptable in educational research $(\alpha \geq$ .70; but see Taber, 2018, for a critical discussion of this convention).

In conclusion, the present study provides new evidence that narrative dialogic reading with wordless picture books has similar positive effects on narrative comprehension skills as it has on vocabulary skills, underlining the versatile potential of picture book reading for the acquisition of different oral language skills. Five months after the intervention, the dialogic reading group still outperformed the comparison groups in inferential narrative comprehension, suggesting that the learning opportunities provided by narrative dialogic reading were more 
effective in supporting the development of this skill than the learning opportunities in other educational (or familial) settings. Our study shows that narrative comprehension questions and wordless picture books are promising modifications of the original dialogic reading intervention that contribute to enhancing the intervention's positive effects on different oral language skills. 


\section{References}

Arizpe, E. (2013). Meaning-making from wordless (or nearly wordless) picture books: What educational research expects and what readers have to say. Cambridge Journal of Education, 43, 163-176. doi:10.1080/0305764x.2013.767879

Bartón, K (2017). MuMIn: Multi-Model Inference. Retrieved May 17, 2018, from https://CRAN.R-project.org/package=MuMIn.

Bates, D., Mächler, M., Bolker, B., \& Walker, S. (2015). Fitting linear mixed-effects models using lme4. Journal of Statistical Software, 67, 1-48. doi:10.18637/jss.v067.i01

Bergman Deitcher, D., Aram, D., \& Johnson, H. (2018). Does book genre matter? Boys' and girls' word learning from narrative and informational books in the preschool years. Journal of Research in Reading, 42, 193-211. doi:10.1111/1467-9817.12266

Blewitt, P., Rump, K. M., Shealy, S. E., \& Cook, S. A. (2009). Shared book reading: When and how questions affect young children's word learning. Journal of Educational Psychology, 101, 294-304. doi:10.1037/a0013844

Bliese, P. D., \& Ployhart, R. E. (2002). Growth modeling using random coefficient models: Model building, testing, and illustrations. Organizational Research Methods, 5, 362-387. doi:10.1177/109442802237116

Chaparro-Moreno, L. J., Reali, F., \& Maldonado-Carreño, C. (2017). Wordless picture books boost preschoolers' language production during shared reading. Early Childhood Research Quarterly, 40, 52-62. doi:10.1016/j.ecresq.2017.03.001

Cohrdes, C., Grolig, L., \& Schroeder, S. (2019). The development of music competencies in preschool children: Effects of a training program and the role of environmental factors. Psychology of Music, 47(3), 358-375. doi:10.1177/0305735618756764 
Coyne, M. D., McCoach, D. B., Loftus, S., Zipoli, R., \& Kapp, S. (2009). Direct vocabulary instruction in kindergarten: Teaching for breadth versus depth. Elementary School Journal, 110,1-48. doi:10.1086/598840

Damhuis, C. M. P., Segers, E., \& Verhoeven, L. (2015). Stimulating breadth and depth of vocabulary via repeated storybook readings or tests. School Effectiveness and School Improvement, 26, 382-396. doi:10.1080/09243453.2014.965181

Debaryshe, B. D. (1993). Joint picture-book reading correlates of early oral language skill. Journal of Child Language, 20, 455-461. doi:10.1017/s0305000900008370

Esser, G. (2002). BUEVA. Basisdiagnostik umschriebener Entwicklungsstörungen im Vorschulalter [Basic assessment of developmental disorders in preschool]. Göttingen, Germany: Hogrefe.

Farrant, B. M., \& Zubrick, S. R. (2013). Parent-child book reading across early childhood and child vocabulary in the early school years: Findings from the Longitudinal Study of Australian Children. First Language, 33, 280-293. doi:10.1177/0142723713487617

Flack, Z. M., Field, A. P., \& Horst, J. S. (2018). The effects of shared storybook reading on word learning: A meta-analysis. Developmental Psychology, 54, 1334-1346. doi:10.1037/dev0000512

Fletcher, K. L., \& Reese, E. (2005). Picture book reading with young children: A conceptual framework. Developmental Review, 25, 64-103. doi:10.1016/j.dr.2004.08.009

Fox, J., \& Weisberg, S. (2011). An $\{R\}$ companion to applied regression, Second Edition. Thousand Oaks, CA: Sage. 
Ganzeboom, H. B. G., \& Treiman, D. J. (1996). Internationally comparable measures of occupational status for the 1988 International Standard Classification of Occupations. Social Science Research, 25, 201-239. doi:10.1006/ssre.1996.0010

Griffin, T., Hemphill, L., Camp, L., \& Wolf, D. P. (2004). Oral discourse in the preschool years and later literacy skills. First Language, 24, 123-147. doi:10.1177/0142723704042369

Grolig, L., Cohrdes, C., \& Schroeder, S. (2017). Der Titelrekognitionstest für das Vorschulalter (TRT-VS): Erfassung des Lesevolumens von präkonventionellen Lesern und Zusammenhänge mit Vorläuferfertigkeiten des Lesens [The Title Recognition Test for Kindergarteners (TRT-VS): Assessment of preconventional readers' print exposure and its relations to precursors of reading]. Diagnostica, 63, 309-319. doi:10.1026/00121924/a000186

Grolig, L., Cohrdes, C., Tiffin-Richards, S. \& Schroeder, S. (2019). Effects of preschoolers' storybook exposure and literacy environments on lower level and higher level language skills. Reading and Writing: An Interdisciplinary Journal, 32, 1061-1084. doi:10.1007/s11145-018-9901-2

Guo, Y., Dynia, J. M., Logan, J. A. R., Justice, L. M., Breit-Smith, A., \& Kaderavek, J. N. (2016). Fidelity of implementation for an early-literacy intervention: Dimensionality and contribution to children's intervention outcomes. Early Childhood Research Quarterly, 37, 165-174. doi:10.1016/j.ecresq.2016.06.001

Huebner, C. E., \& Meltzoff, A. N. (2005). Intervention to change parent-child reading style: A comparison of instructional methods. Journal of Applied Developmental Psychology, 26, 296-313. doi:10.1177/1468798409356987 
Hothorn, T., Bretz, F., \& Westfall, P. (2008). Simultaneous inference in general parametric models. Biometrical Journal, 50, 346-363. doi:10.1002/bimj.200810425

Kintsch, W. (1998). Comprehension: A paradigm for cognition. New York, NY: Cambridge University Press.

Krahn, F. (1979). Robot-bot-bot. New York, NY: Dutton.

Lenhart, J., Lenhard, W., Vaahtoranta, E., \& Suggate, S. (2019). The effects of questions during shared-reading: Do demand-level and placement really matter? Early Childhood Research Quarterly, 47, 49-61. doi:10.1016/j.ecresq.2018.10.006

Lepola, J., Lynch, J., Kiuru, N., Laakkonen, E., \& Niemi, P. (2016). Early oral language comprehension, task orientation, and foundational reading skills as predictors of grade 3 reading comprehension. Reading Research Quarterly, 51, 373-390. doi:10.1002/rrq.145

Lepola, J., Lynch, J., Laakkonen, E., Silvén, M., \& Niemi, P. (2012). The role of inference making and other language skills in the development of narrative listening comprehension in 4-6-year-old children. Reading Research Quarterly, 47, 259-282. doi:10.1002/rrq.020

Lever, R., \& Sénéchal, M. (2011). Discussing stories: On how a dialogic reading intervention improves kindergartners' oral narrative construction. Journal of Experimental Child Psychology, 108, 1-24. doi:10.1016/j.jecp.2010.07.002

Lonigan, C. J., Purpura, D. J., Wilson, S. B., Walker, P. M., \& Clancy-Menchetti, J. (2013). Evaluating the components of an emergent literacy intervention for preschool children at risk for reading difficulties. Journal of Experimental Child Psychology, 114, 111-130. doi:10.1016/j.jecp.2012.08.010 
Lysaker, J. T., \& Miller, A. (2012). Engaging social imagination: The developmental work of wordless book reading. Journal of Early Childhood Literacy, 13, 147-174. doi: $10.1177 / 1468798411430425$

Morrow, L. M. (1984). Reading stories to young children: Effects of story structure and traditional questioning strategies on comprehension. Journal of Reading Behavior, 16, 273-288. doi:10.1080/10862968409547521

Mascareño, M., Snow, C. E., Deunk, M. I., \& Bosker, R. J. (2016). Language complexity during read-alouds and kindergartners' vocabulary and symbolic understanding. Journal of Applied Developmental Psychology, 44, 39-51. doi:10.1016/j.appdev.2016.02.001

Massaro, D. W. (2015). Two different communication genres and implications for vocabulary development and learning to read. Journal of Literacy Research, 47, 505-527. doi:10.1177/1086296x 15627528

Mayer, M. (1969). Frog, where are you? New York, NY: Dial Press.

Mayer, M. (1973). Frog on his own. New York, NY: Dial Press.

Mayer, M. (1975). One frog too many. New York, NY: Dial Press.

Mol, S. E., Bus, A. G., \& de Jong, M. T. (2009). Interactive book reading in early education: A tool to stimulate print knowledge as well as oral language. Review of Educational Research, 79, 979-1007. doi:10.3102/0034654309332561

Montag, J. L., Jones, M. N., \& Smith, L. B. (2015). The words children hear: Picture books and the statistics for language learning. Psychological Science, 26, 1489-1496. doi:10.1177/0956797615594361 
Nakagawa, S., \& Schielzeth, H. (2012). A general and simple method for obtaining $R 2$ from generalized linear mixed-effects models. Methods in Ecology and Evolution, 4, 133-142. doi:10.1111/j.2041-210x.2012.00261.x

Noble, C., Sala, G., Peter, M., Lingwood, J., Rowland, C. F., Gobet, F., \& Pine, J. (2019). The Impact of Shared Book Reading on Children's Language Skills: A Meta-Analysis. Educational Research Review, 28. Advance online publication. https://doi.org/10.1016/j.edurev.2019.100290

Nykrin, R., Grüner, M., \& Widmer, M. (2007). Musik und Tanz für Kinder [Music and dance for children]. Mainz, Germany: Schott.

Ouellette, G. P. (2006). What's meaning got to do with it: The role of vocabulary in word reading and reading comprehension. Journal of Educational Psychology, 98, 554-566. doi:10.1037/0022-0663.98.3.554

Paris, A. H., \& Paris, S. G. (2003). Assessing narrative comprehension in young children. Reading Research Quarterly, 38, 36-76. doi:10.1598/rrq.38.1.3

Paris, A. H., \& Paris, S. G. (2007). Teaching narrative comprehension strategies to first graders. Cognition and Instruction, 25, 1-44. doi:10.1080/07370000709336701

Petermann, F. (2009). Wechsler Preschool and Primary Scale of Intelligence - III. German version. Frankfurt, Germany: Pearson.

R Core Team (2017). R: A language and environment for statistical computing [Computer software]. Vienna, Austria: R Foundation for Statistical Computing. Retrieved May 17, 2018, from https://www.R-project.org

Raudenbush, S. W., \& Bryk, A. S. (2002). Hierarchical linear models: Applications and data analysis methods. Second Edition. Thousand Oaks, CA: Sage 
Schroeder, S., \& Grolig, L. (2018) Fostering Language Skills in Preschool Using Musical Training: Opportunities and Challenges. In Rat für Kulturelle Bildung e.V. (Ed.): Research on Impacts of Arts Education: German-Dutch Perspectives. Retrieved from https://www.lkca.nl/ /media/kennisbank/publicaties/2018/n-s/publikation\%20germandutch\%20colloquium.pdf

Schroeder, S., Würzner, K.-M., Heister, J., Geyken, A., \& Kliegl, R. (2015). childLex: A lexical database of German read by children. Behavior Research Methods, 47, 1085-1094. doi:10.3758/s13428-014-0528-1

Sénéchal, M., \& LeFevre, J.-A. (2002). Parental involvement in the development of children’s reading skill: A five-year longitudinal study. Child Development, 73, 445-460. doi:10.1111/1467-8624.00417

Sénéchal, M., LeFevre, J. A., \& Lawson, E. P. (1996). Knowledge of storybooks as a predictor of young children's vocabulary. Journal of Educational Psychology, 88, 520-536. doi:10.1037/0022-0663.88.3.520

Silva, M., \& Cain, K. (2015). The relations between lower and higher level comprehension skills and their role in prediction of early reading comprehension. Journal of Educational Psychology, 107, 321-331. doi:10.1037/a0037769

Silva, M., \& Cain, K. (2017). The use of questions to scaffold narrative coherence and cohesion. Journal of Research in Reading, 42(1), 1-17. doi:10.1111/1467-9817.12129

Silva, M., Strasser, K., \& Cain, K. (2014). Early narrative skills in Chilean preschool: Questions scaffold the production of coherent narratives. Early Childhood Research Quarterly, 29, 205-213. doi:10.1016/j.ecresq.2014.02.002 
Sim, S., Berthelsen, D., Walker, S., Nicholson, J. M., \& Fielding-Barnsley, R. (2014). A shared reading intervention with parents to enhance young children's early literacy skills. Early Child Development and Care, 184, 1531-1549. doi:10.1080/03004430.2013.862532

Stein, N., \& Glenn, C. (1979). An analysis of story comprehension in elementary school children. In R. O. Freeble (Ed.), Advances in discourse processing, Vol. 2: New directions in discourse processing (pp. 53-120). Norwood, NJ: Ablex.

Taber, K. S. (2018). The use of Cronbach's alpha when developing and reporting research instruments in science education. Research in Science Education, 48, 1273-1296. doi:10.1007/s11165-016-9602-2

van den Broek, P., Kendeou, P., Lousberg, S., \& Visser, G. (2017). Preparing for reading comprehension: Fostering text comprehension skills in preschool and early elementary school children. International Electronic Journal Of Elementary Education, 4, 259-268. Retrieved from https://www.iejee.com/index.php/IEJEE/article/view/223

van Kleeck, A. (2003). Research on book sharing: Another critical look. In A. van Kleeck, S. Stahl, \& E. Bauer (Eds.), On reading books to children: Parents and teachers. (pp. 271320). Mahwah, NJ: Erlbaum. doi:10.4324/9781410607355

van Kleeck, A. (2008). Providing preschool foundations for later reading comprehension: The importance of and ideas for targeting inferencing in storybook-sharing interventions. Psychology in the Schools, 45, 627-643. doi:10.1002/pits.20314

van Kleeck, A., Gillam, R. B., Hamilton, L., \& McGrath, C. (1997). The relationship between middle-class parents' book sharing discussion and their preschoolers' abstract language development. Journal of Speech, Language, and Hearing Research, 40, 1261-1271. doi:10.1044/jslhr.4006.1261 
van Kleeck, A., Vander Woude, J., \& Hammett, L. (2006). Fostering literal and inferential language skills in Head Start preschoolers with language impairment using scripted booksharing discussions. American Journal of Speech-Language Pathology, 15, 85-95. doi:10.1044/1058-0360(2006/009).

Wasik, B. A., Hindman, A. H., \& Snell, E. K. (2016). Book reading and vocabulary development: A systematic review. Early Childhood Research Quarterly, 37, 39-57. doi:10.1016/j.ecresq.2016.04.003

Weiß, R. H., \& Osterland, J. (2013). CFT 1-R. Grundintelligenztest Skala 1: Revision [Culture fair intelligence test - revised German version]. Göttingen, Germany: Hogrefe.

Whitehurst, G. J., Epstein, J. N., Angell, A. L., Payne, A. C., Crone, D. A., \& Fischel, J. E. (1994). Outcomes of an emergent literacy intervention in Head Start. Journal of Educational Psychology, 86, 542-555. doi:10.1037//0022-0663.86.4.542

Whitehurst, G. J., Zevenbergen, A. A., Crone, D. A., Schultz, M. D., Velting, O. N., \& Fischel, J. E. (1999). Outcomes of an emergent literacy intervention from Head Start through second grade. Journal of Educational Psychology, 91, 261-272.

Wirts, C., Egert, F., \& Reber, K. (2017). Early literacy in deutschen Kindertageseinrichtungen. Eine Analyse der Häufigkeit von Literacy-Aktivitäten im Kita-Alltag [Early literacy in German early child education and care: Analysis on the frequency of early literacy activities during a day]. Forschung Sprache, 2, 96-106. Retrieved from https://www.forschung-sprache.eu

Wright, H. H., Capilouto, G. J., Srinivasan, C., \& Fergadiotis, G. (2011). Story processing ability in cognitively healthy younger and older adults. Journal of Speech, Language, and Hearing Research, 54, 900-917. doi:10.1044/1092-4388(2010/09-0253) 
Yuill, N., \& Oakhill, J. (1991). Children's problems in text comprehension: An experimental investigation. Cambridge, UK: Cambridge University Press.

Zevenbergen, A. A., \& Whitehurst, G. J. (2003). Dialogic reading: A shared picture book intervention for preschoolers. In A. van Kleeck, S. Stahl, \& E. Bauer (Eds.), On reading books to children: Parents and teachers. (pp. 177-200). Mahwah, NJ: Erlbaum. doi:10.4324/9781410607355

Zevenbergen, A. A., Whitehurst, G. J., \& Zevenbergen, J. A. (2003). Effects of a shared-reading intervention on the inclusion of evaluative devices in narratives of children from lowincome families. Journal of Applied Developmental Psychology, 24, 1-15. doi:10.1016/s0193-3973(03)00021-2

Zucker, T. A., Cabell, S. Q., Justice, L. M., Pentimonti, J. M., \& Kaderavek, J. N. (2013). The role of frequent, interactive prekindergarten shared reading in the longitudinal development of language and literacy skills. Developmental Psychology, 49, 1425-1439. doi:10.1037/a0030347 
Supplemental Materials 


\section{Supplemental materials}

Grolig, L., Cohrdes, C., Tiffin-Richards, S. P., \& Schroeder, S. (2020). Narrative dialogic reading with wordless picture books: A cluster-randomized intervention study. Early Childhood Research Quarterly, 51, 191-203. doi:10.1016/j.ecresq.2019.11.002

Table S1

Books Used in the Dialogic Reading Intervention

\begin{tabular}{|c|c|}
\hline Author & Title and publisher \\
\hline Badel, R. (2013). & Der fette Fang [The big catch]. Wuppertal: Hammer. \\
\hline Becker, A. (2015). & Die Reise [The journey]. Hildesheim: Gerstenberg \\
\hline Becker, A. (2016). & Die Suche [Quest]. Hildesheim: Gerstenberg \\
\hline Briggs, R. (2005). & Der Schneemann [The Snowman]. Hamburg: Aladin. \\
\hline Haughton, C. (2015). & $\begin{array}{l}\text { Psst! Wir haben einen Vogel [Shh! We Have a Plan]. Frankfurt: } \\
\text { Fischer. }\end{array}$ \\
\hline Heidelbach, N. (2007). & $\begin{array}{l}\text { Ein Buch für Bruno [A book for Bruno]. Weinheim and Basel: } \\
\text { Beltz. }\end{array}$ \\
\hline $\begin{array}{l}\text { Holzwarth, W. \& } \\
\text { Strozyk, T. (2015). }\end{array}$ & Mag ich! Gar nicht! [Don't like it! Not at all!]. Leipzig: Klett. \\
\hline Mitgutsch, A. (2012). & $\begin{array}{l}\text { Mein großes Winter-Wimmelbuch [My big winter wimmelbook]. } \\
\text { Ravensburg: Ravensburger. }\end{array}$ \\
\hline Mitgutsch, A. (2015). & $\begin{array}{l}\text { Mein Wimmelbuch: Komm mit ans Wasser [My Wimmelbook: Come } \\
\text { with us to the water]. Ravensburg: Ravensburger. }\end{array}$ \\
\hline Muller, G. (2000) & Was war hier bloß los? [What happened here?]. Frankfurt: Moritz. \\
\hline Muzo (2011). & Gute Reise, kleine Wolke [Safe journey, little cloud]. Baar: Aracari. \\
\hline Sendak, M. (1967). & $\begin{array}{l}\text { Wo die wilden Kerle wohnen [Where the wild things are]. Zurich: } \\
\text { Diogenes. }\end{array}$ \\
\hline Riphagen, L. (2011) & So ein Tohuwabohu! [Animals Home Alone]. Cologne: Boje. \\
\hline Rodriguez, B. (2008). & Der Hühnerdieb [The chicken thief]. Wuppertal: Hammer. \\
\hline Rodriguez, B. (2012). & Das Hühnerglück [The lucky chicken]. Wuppertal: Hammer. \\
\hline Schössow, P. (2010). & Meehr!! [Mooore!!]. Munich: Hanser. \\
\hline $\begin{array}{l}\text { Tolman, M. \& Tolman, } \\
\text { R. (2010). }\end{array}$ & Das Baumhaus [The tree house]. Berlin: Berlin Press. \\
\hline Wiesner, D. (2007). & Strandgut[Flotsam]. Hamburg: Carlsen. \\
\hline Wiesner, D. (2014). & Herr Schnuffels [Mr Wuffles!]. Hamburg: Aladin. \\
\hline
\end{tabular}


Table S2

Stimuli for Narrative Production Task by Measurement Point

\begin{tabular}{lllll}
\hline & & \multicolumn{3}{c}{ Main Points } \\
\cline { 3 - 5 } Measurement point & Book & Total & Inferential & Literal \\
\hline Pretest & Frog on his own & 32 & 12 & 20 \\
Posttest & Frog, where are you? & 42 & 15 & 27 \\
Follow-Up I & Robot-bot-bot & 30 & 11 & 19 \\
Follow-Up II & One frog too many & 37 & 14 & 23 \\
\hline
\end{tabular}

Note. Number of items is displayed. 
Table S3

Items of the Vocabulary Breadth Test

\begin{tabular}{cl}
\hline Number & Item \\
\hline 1 & Segelschiff [sailing ship] \\
2 & Laterne [lantern] \\
3 & Wasserschlange [water snake] \\
4 & Vollmond [full moon] \\
5 & Ruderboot [rowboat] \\
6 & Krake [octopus] \\
7 & Heißluftballon [hot-air balloon] \\
8 & Seetang [seaweed] \\
9 & Strickleiter [rope ladder] \\
10 & Anorak [anorak] \\
11 & Labyrinth [maze] \\
12 & Iglu [igloo] \\
13 & Strandkorb [beach chair] \\
14 & Tipi [tepee] \\
\hline 15 & Kescher [landing net] \\
\hline 1 & \\
\hline 1 & \\
\hline 1 &
\end{tabular}


Narrative Comprehension Questions

and Examples of 0-, 1-, and 2-Point Responses

\section{Story: "Frog on His Own" (Pretest)}

Coding scheme taken from: Silva, M., \& Cain, K. (2015). The relations between lower and higher level comprehension skills and their role in prediction of early reading comprehension.

Journal of Educational Psychology, 107, 321-331. doi:10.1037/a0037769

Coding scheme available at

http://supp.apa.org/psycarticles/supplemental/a0037769/a0037769 supp.html 


\section{Story: “Frog, where are you?” (Posttest)}

1. Characters: Who are the characters in the story? (Explicit)

2-point response: states that characters are a boy, his dog, and a frog

1-point response: includes two of three main characters

0-point response: provides only one character or response inappropriate

2. Setting: Where does this story happen? (Explicit)

2-point response: includes multiple scenarios

1-point response: includes one scenario

0 -oint response: no answer or an inappropriate setting

3. Initiating Event: What do you think happens here? Why is this an important part of the story? (Explicit)

2-point response: the initiating event is identified and connected to other events/pages

1-point response: the initiating event is identified but it is not connected to other events/pages

0-point response: no answer or an the initiating event was not identified

The picture: The boy and the dog lie sleeping in bed. The frog climbs out of the jar.

4. Problem: If you were telling your friend this story, what would you say is going on now? Why did this happen? (Explicit)

2-point response: identifies the problem and also a connection to other events/pages of the story

1-point response: identifies the problem but it is not connected to other events/pages

0-point response: no answer or the problem was not identified

The picture: The boy looks into a boot to check whether the frog is there. The dog searches the frog in a jar.

5. Dialogue: What do you think the boy would be saying here? Why would you say that? (Implicit)

2-point response: includes an appropriate dialogue that can be connected to other events/pages

1-point response: includes an appropriate dialogue but it is not connected to other events/pages

0-point response: no answer or an inappropriate dialogue

The picture: The boy and the dog stand on a meadow. The boy makes a funnel with his hands and calls something.

6. Thoughts: What do you think the young boy is thinking here? Why would he think that? (Implicit)

2-point response: an appropriate thought is inferred and connected to other events/pages

1-point response: includes an appropriate thought but it is not connected to other events/pages

0-point response: no answer or an inappropriate thought

The picture: The boy is holding his nose. A rodent looks out of an earth hole. In the background, the dog barks at a bee hive. 
7. Feelings: What do you think the boy is feeling here? Why do you think so? (Implicit)

2-point response: an appropriate feeling is identified and connected to other events/pages

1-point response: an appropriate feeling is identified but it is not connected to other events/pages

0-point response: no answer or not feelings are identified

The picture: The deer stops shortly before a cliff. The boy and the dog fall down. The boy stretches his arms and has an open mouth.

8. Resolution: What happened here? Why does this happen? (Explicit)

2-point response: identifies the resolutions and it is connected to other events/pages of the story

1-point response: identifies the resolution but no connection to other events/pages is provided

0 -point response: no answer or the resolution is not identified

The picture: The boy and the dog climb over a tree. Behind, they find the frog and his family. A small

frog jumps near the boy.

9. Prediction: This is the last picture of the story. What do you think happens next? Why do you think so? (Implicit)

2-point response: is related to the events of the story but goes beyond the picture (the last picture of the story)

1-point response: is based only on the information of the last picture

0 -point response: no answer or prediction is given

The picture: The boy and the dog leave the frog family. The boy waves goodbye to the frog family. He is holding a small frog in his other hand.

10. Theme: Think about everything that you learned from reading this book. What advice would you give to the boy or the frog so that the same thing doesn't happen again? Why would you say that? (Implicit)

2-point response: provides integration of multiple events of the story

1-point response: uses information of only one aspect of the story

0 -point response: no answer or inadequate answer 


\section{Story: "Robot-bot-bot" (Follow-Up I)}

Coding scheme taken from: Paris, A. H., \& Paris, S. G. (2003). Assessing narrative comprehension in young children. Reading Research Quarterly, 38, 36-76.

doi:10.1598/rrq.38.1.3 (Appendices B and C) 


\section{Story: "One frog too many" (Follow-Up II)}

1. Characters: Who are the characters in the story? (Explicit)

2-point response: states that characters are a boy, his dog, a turtle, a big frog, and a small frog

1-point response: includes three of five main characters

0 -point response: provides only two characters or response inappropriate

2. Setting: Where does this story happen? (Explicit)

2-point response: includes multiple scenarios

1-point response: includes one scenario

0-point response: no answer or an inappropriate setting

3. Initiating Event: What do you think happens here? Why is this an important part of the story?

(Explicit)

2-point response: the initiating event is identified and connected to other events/pages

1-point response: the initiating event is identified but it is not connected to other events/pages

0 -point response: no answer or an the initiating event was not identified

The picture: The boy has opened the parcel and takes out the small frog. The big frog looks away. He is angry.

4. Problem: If you were telling your friend this story, what would you say is going on now? Why did this happen? (Explicit)

2-point response: identifies the problem and also a connection to other events/pages of the story

1-point response: identifies the problem but it is not connected to other events/pages

0-point response: no answer or the problem was not identified

The picture: The big frog pushes the small frog from the turtle's back. The small frog is surprised and falls onto the ground.

5. Dialogue: What do you think the boy would be saying here? Why would you say that? (Implicit)

2-point response: includes an appropriate dialogue that can be connected to other events/pages

1-point response: includes an appropriate dialogue but it is not connected to other events/pages

0-point response: no answer or an inappropriate dialogue

The picture: The boy stands with one foot on the raft. The big frog sits onshore and looks angrily away from the boy. The boy is angry with the big frog. The other animals sit on the raft.

6. Thoughts: What do you think the young boy is thinking here? Why would he think that? (Implicit)

2-point response: an appropriate thought is inferred and connected to other events/pages.

1-point response: includes an appropriate thought but it is not connected to other events/pages.

0-point response: no answer or an inappropriate thought. 
The picture: They are on the raft. The small frog is missing because the big frog has pushed him into the water. The boy has his mouth open and looks scared.

7. Feelings: What do you think the frog is feeling here? Why do you think so? (Implicit)

2-point response: an appropriate feeling is identified and connected to other events/pages.

1-point response: an appropriate feeling is identified but it is not connected to other events/pages.

0-point response: no answer or not feelings are identified.

The picture: The boy, the turtle, and the dog go away from the raft. The boy is crying. The dog growls at the big frog who sits on the shore and looks sad.

8. Resolution: What happened here? Why does this happen? (Explicit)

2-point response: identifies the resolutions and it is connected to other events/pages of the story.

1-point response: identifies the resolution but no connection to other events/pages is provided.

0 -point response: no answer or the resolution is not identified.

The picture: The boy and the dog sit on the bed. The small frog snuggles with the big frog. The big frog is happy.

9. Prediction: This is the last picture of the story. What do you think happens next? Why do you think so? (Implicit)

2-point response: is related to the events of the story but goes beyond the picture (the last picture of the story).

1-point response: is based only on the information of the last picture.

0 -point response: no answer or prediction is given.

The picture: The boy and the dog sit on the bed. The small frog snuggles with the big frog. The big frog is happy.

10. Theme: Think about everything that you learned from reading this book. What advice would you give to the boy or the frog so that the same thing doesn't happen again? Why would you say that? (Implicit) 2-point response: provides integration of multiple events of the story.

1-point response: uses information of only one aspect of the story.

0-point response: no answer or inadequate answer 


\section{Narrative Production Main Point Items}

The main points were derived from narratives collected in a pilot study with university students (16 female, 14 male; $M_{\text {age }}=23.9$ years, $S D=4.4$ years). Students received 20 Euros as reimbursement for study participation. Idea units that were mentioned in at least $60 \%$ of the narratives were categorized as main points and subsequently used for coding the children's narratives.

Table S4

Main Point Items and Mean Proportion Produced for Pretest Story "Frog on his own"

\begin{tabular}{|c|c|c|c|c|}
\hline \multirow[t]{2}{*}{ Main point } & \multirow[t]{2}{*}{ Type } & \multirow[t]{2}{*}{ Element } & \multicolumn{2}{|c|}{ Proportion } \\
\hline & & & $\begin{array}{l}\text { Adults } \\
(N=30)\end{array}$ & $\begin{array}{c}\text { Children } \\
(N=197)\end{array}$ \\
\hline In a park, & literal & setting & 0.97 & 0.14 \\
\hline there is a boy with his dog and his frog. & literal & character & 1.00 & 0.41 \\
\hline They go for a stroll. & literal & event & 1.00 & 0.75 \\
\hline The frog sits in a bucket. & literal & setting & 0.77 & 0.21 \\
\hline He jumps out. & literal & initiating event & 0.93 & 0.45 \\
\hline The boy doesn't notice. & inferential & thought & 0.63 & 0.08 \\
\hline A couple & literal & character & 0.97 & 0.38 \\
\hline is having a picknick. & literal & event & 0.73 & 0.29 \\
\hline The frog goes into their basket. & inferential & motive & 0.97 & 0.25 \\
\hline Then he is holding on to a woman's arm. & literal & problem & 0.73 & 0.61 \\
\hline The woman is furious. & inferential & emotion & 0.97 & 0.37 \\
\hline She shouts at him. & inferential & dialogue & 0.67 & 0.10 \\
\hline The frog jumps away. & literal & resolution & 0.80 & 0.49 \\
\hline He is at a pond. & literal & setting & 0.73 & 0.15 \\
\hline A mother sits with a buggy, & literal & character & 1.00 & 0.44 \\
\hline a baby, and a cat. & literal & character & 0.63 & 0.21 \\
\hline The frog watches the mother. & inferential & thought & 0.93 & 0.14 \\
\hline She is reading. & literal & event & 0.70 & 0.22 \\
\hline The mother is distracted. & inferential & thought & 0.70 & 0.09 \\
\hline She doesn't' notice that the frog jumps into the buggy. & inferential & thought & 0.73 & 0.07 \\
\hline The frog drinks the milk. & literal & event & 0.83 & 0.66 \\
\hline The baby is cross. & inferential & emotion & 0.87 & 0.33 \\
\hline The cat jumps onto the frog. & literal & problem & 0.80 & 0.71 \\
\hline The cat wants to catch it. & inferential & motive & 0.97 & 0.25 \\
\hline The frog runs away. & literal & event & 0.67 & 0.27 \\
\hline The buggy falls over. & literal & setting & 0.63 & 0.30 \\
\hline The baby cries. & inferential & emotion & 0.90 & 0.69 \\
\hline The cat sits on the frog. & literal & event & 1.00 & 0.77 \\
\hline The boy returns. & literal & resolution & 0.87 & 0.22 \\
\hline He rescues the frog. & inferential & motive & 0.97 & 0.59 \\
\hline The frog is happy. & inferential & emotion & 0.70 & 0.13 \\
\hline They go home. & literal & setting & 0.90 & 0.72 \\
\hline & & & $\begin{array}{l}M=0.83 \\
S D=0.13\end{array}$ & $\begin{array}{c}M=0.36 \\
S D=0.22\end{array}$ \\
\hline
\end{tabular}


Table S5

Main Point Items and Mean Proportion Produced for Posttest Story "Frog, where are you?"

\begin{tabular}{|c|c|c|c|c|}
\hline \multirow[t]{2}{*}{ Main point } & \multirow[t]{2}{*}{ Type } & \multirow[t]{2}{*}{ Element } & \multicolumn{2}{|c|}{ Proportion } \\
\hline & & & $\begin{array}{l}\text { Adults } \\
(N=30)\end{array}$ & $\begin{array}{c}\text { Children } \\
(N=188)\end{array}$ \\
\hline A boy is with his dog and a frog & literal & character & 1.00 & 0.53 \\
\hline in his room. & literal & setting & 0.73 & 0.04 \\
\hline The frog is caught in a jar. & literal & initiating event & 0.97 & 0.44 \\
\hline The boy and the dog sleep. & literal & initiating event & 1.00 & 0.81 \\
\hline The frog escapes. & inferential & motive & 0.93 & 0.78 \\
\hline The next morning, & literal & setting & 0.87 & 0.26 \\
\hline the boy wakes up. & literal & event & 0.83 & 0.46 \\
\hline The frog is gone. & literal & problem & 0.93 & 0.67 \\
\hline The boy is sad. & inferential & emotion & 0.70 & 0.08 \\
\hline He wants to find the frog. & inferential & motive & 0.63 & 0.55 \\
\hline He searches the frog in the room. & literal & event & 0.97 & 0.47 \\
\hline He goes to the window and calls the frog. & inferential & dialogue & 0.93 & 0.44 \\
\hline They want to find the frog & inferential & motive & 0.87 & 0.60 \\
\hline in the woods. & literal & setting & 0.70 & 0.24 \\
\hline An animal bites the boy. & literal & event & 0.93 & 0.48 \\
\hline The dog barks at some bees. & literal & event & 0.60 & 0.34 \\
\hline He shakes down the bee hive. & literal & problem & 0.67 & 0.53 \\
\hline The bees attack him. & literal & event & 0.87 & 0.63 \\
\hline The dog is scared and flees. & inferential & emotion & 0.63 & 0.18 \\
\hline The boy shouts into & inferential & dialogue & 0.67 & 0.51 \\
\hline a hole in a tree. & literal & setting & 0.60 & 0.42 \\
\hline He thinks that the frog is inside. & inferential & thought & 0.97 & 0.26 \\
\hline An owl wants to chase away the boy. & inferential & motive & 0.70 & 0.58 \\
\hline He startles. & inferential & emotion & 0.60 & 0.15 \\
\hline The boy falls off the tree. & literal & event & 0.77 & 0.50 \\
\hline He climbs & literal & event & 0.83 & 0.42 \\
\hline on a rock. & literal & setting & 0.93 & 0.48 \\
\hline He calls the frog. & inferential & dialogue & 0.63 & 0.34 \\
\hline A deer & literal & character & 0.63 & 0.90 \\
\hline takes the boy on his head. & literal & problem & 0.97 & 0.63 \\
\hline The dog escapes from the bees. & literal & resolution & 0.73 & 0.15 \\
\hline Deer, boy and dog come to a cliff. & literal & setting & 0.73 & 0.22 \\
\hline The boy and the dog fall down. & literal & event & 0.73 & 0.62 \\
\hline They land in water. & literal & resolution & 0.97 & 0.89 \\
\hline The boy notices something. & inferential & thought & 0.67 & 0.08 \\
\hline He thinks that there is something behind a tree. & inferential & thought & 0.87 & 0.65 \\
\hline They find the frog. & literal & resolution & 1.00 & 0.87 \\
\hline There are many other frogs. & literal & character & 0.93 & 0.56 \\
\hline
\end{tabular}


The boy is happy.

\begin{tabular}{llcc} 
inferential & emotion & 0.73 & 0.08 \\
literal & event & 0.73 & 0.55 \\
literal & character & 0.80 & 0.47 \\
inferential & dialogue & 0.67 & 0.33 \\
\hline & & $M=0.80$ & $M=0.46$ \\
& & $S D=0.14$ & $S D=0.23$ \\
\hline
\end{tabular}

Table S6

Main Point Items and Mean Proportion Produced for Follow-up I Story "Robot-bot-bot"

\begin{tabular}{|c|c|c|c|c|}
\hline \multirow[t]{2}{*}{ Main point } & \multirow[t]{2}{*}{ Type } & \multirow[t]{2}{*}{ Element } & \multicolumn{2}{|c|}{ Proportion } \\
\hline & & & $\begin{array}{c}\text { Adults } \\
(N=30)\end{array}$ & $\begin{array}{c}\text { Children } \\
(N=143)\end{array}$ \\
\hline A girl waves to her & inferential & motive & 0.90 & 0.08 \\
\hline father. & literal & character & 0.70 & 0.35 \\
\hline The father has a packet in his car. & literal & setting & 0.90 & 0.34 \\
\hline They go inside. & literal & setting & 0.77 & 0.21 \\
\hline The family & literal & character & 1.00 & 0.29 \\
\hline is curious. & inferential & emotion & 0.60 & 0.13 \\
\hline They wonder what might be in the packet. & inferential & thought & 1.00 & 0.83 \\
\hline It's a robot. & literal & character & 1.00 & 0.96 \\
\hline They try out the robot. & literal & event & 0.93 & 0.65 \\
\hline It cleans the dishes. & literal & event & 1.00 & 0.86 \\
\hline It brings out the trash. & literal & event & 1.00 & 0.92 \\
\hline The family is happy with the robot. & inferential & emotion & 0.87 & 0.23 \\
\hline The parents chat and dance. & inferential & dialogue & 0.70 & 0.21 \\
\hline The girl is curious. & inferential & thought & 0.77 & 0.90 \\
\hline She wants to look inside the robot. & inferential & motive & 0.67 & 0.24 \\
\hline She opens the robot. & literal & event & 0.87 & 0.68 \\
\hline She pulls out cables. & literal & event & 0.77 & 0.63 \\
\hline She ties them into a knot. & literal & initiating event & 0.80 & 0.34 \\
\hline She turns on the robot. & literal & event & 0.63 & 0.51 \\
\hline The robot becomes mad. & inferential & thought & 0.83 & 0.48 \\
\hline It rushes into the living room. & literal & problem & 0.67 & 0.23 \\
\hline It throws the father out of the chair. & literal & event & 0.87 & 0.32 \\
\hline The father is scared. & inferential & emotion & 0.70 & 0.14 \\
\hline The living room is trashed. & literal & setting & 0.63 & 0.40 \\
\hline The robot goes out of the window. & literal & resolution & 1.00 & 0.46 \\
\hline It lands in a trash can. & literal & event & 1.00 & 0.75 \\
\hline A garbage collector puts the trash into a truck. & literal & problem & 0.60 & 0.51 \\
\hline The family shouts at him. & inferential & dialogue & 0.93 & 0.61 \\
\hline They want their robot back. & inferential & motive & 0.80 & 0.38 \\
\hline Father and daughter repair the robot. & literal & resolution & 0.97 & 0.90 \\
\hline & & & $\begin{array}{c}M=0.83 \\
S D=0.14\end{array}$ & $\begin{array}{c}M=0.48 \\
S D=0.27\end{array}$ \\
\hline
\end{tabular}


Table S7

Main Point Items and Mean Proportion Produced for Follow-up II Story "One frog too many"

\begin{tabular}{|c|c|c|c|c|}
\hline \multirow[t]{2}{*}{ Main point } & \multirow[t]{2}{*}{ Type } & \multirow[t]{2}{*}{ Element } & \multicolumn{2}{|c|}{ Proportion } \\
\hline & & & $\begin{array}{c}\text { Adults } \\
(N=30)\end{array}$ & $\begin{array}{c}\text { Children } \\
(N=129)\end{array}$ \\
\hline A boy has a frog, a dog, and a turtle. & literal & character & 1.00 & 0.95 \\
\hline The boy gets a present. & literal & setting & 1.00 & 0.96 \\
\hline He opens it. & literal & initiating event & 0.97 & 0.68 \\
\hline It's a small frog. & literal & character & 1.00 & 0.90 \\
\hline The boy introduces the small frog to his animal friends. & inferential & dialogue & 0.70 & 0.39 \\
\hline Everybody cheers except for the big frog. & inferential & emotion & 0.83 & 0.56 \\
\hline They go out & literal & event & 0.97 & 0.68 \\
\hline into the woods. & literal & setting & 0.77 & 0.13 \\
\hline The animals follow the boy. & literal & event & 0.70 & 0.40 \\
\hline The frogs sit on the turtle. & literal & setting & 0.90 & 0.69 \\
\hline The big frog does not like the small frog. & inferential & motive & 1.00 & 0.86 \\
\hline He pushes the small frog from the turtle back. & literal & problem & 1.00 & 0.98 \\
\hline The small frog cries. & inferential & emotion & 0.97 & 0.68 \\
\hline The boy shouts at the big frog. & inferential & dialogue & 0.90 & 0.60 \\
\hline They come to water. & literal & setting & 0.67 & 0.15 \\
\hline The boy tells the big frog not to come with them. & inferential & dialogue & 0.67 & 0.18 \\
\hline The boy and the other animals go on a raft. & literal & event & 0.97 & 0.56 \\
\hline The big frog stays at land. & literal & resolution & 0.63 & 0.61 \\
\hline The boy is distracted. & inferential & thought & 0.77 & 0.25 \\
\hline The big frog jumps onto the raft. & literal & initiating event & 1.00 & 0.92 \\
\hline He pushes the small frog from the raft. & literal & problem & 1.00 & 0.98 \\
\hline The small frog falls into the water. & literal & problem & 0.73 & 0.59 \\
\hline The turtle alarms the boy. & inferential & motive & 0.90 & 0.19 \\
\hline The boy is shocked. & inferential & emotion & 0.90 & 0.65 \\
\hline They search for the small frog. & literal & event & 1.00 & 0.95 \\
\hline They want to rescue him. & inferential & motive & 1.00 & 0.06 \\
\hline They don't find the small frog. & literal & event & 0.97 & 0.58 \\
\hline They feel sad. & inferential & emotion & 1.00 & 0.86 \\
\hline At home, & literal & setting & 0.60 & 0.21 \\
\hline the boy lies on his bed. & literal & event & 0.90 & 0.43 \\
\hline The dog licks his arm. & literal & event & 0.80 & 0.29 \\
\hline They notice a sound from outside. & inferential & thought & 0.87 & 0.26 \\
\hline They look expectantly at the window. & inferential & motive & 0.60 & 0.29 \\
\hline The small frog jumps into the room. & literal & resolution & 1.00 & 0.95 \\
\hline He lands on the big frog. & literal & event & 0.77 & 0.70 \\
\hline The two frogs are friends now. & literal & resolution & 0.80 & 0.77 \\
\hline Everybody is happy. & inferential & emotion & 0.97 & 0.70 \\
\hline
\end{tabular}

